Research Article

\title{
Multiligand Europium Complexes Incorporated Polyvinylpyrrolidone for Enhanced Solar Cell
}

\author{
Zhimin Yu, ${ }^{1}$ Jing Guo, ${ }^{1}$ Desheng Li $\mathbb{D}^{2},{ }^{2}$ and Hai Lin $\mathbb{D}^{1,2}$ \\ ${ }^{1}$ School of Textile and Material Engineering, Dalian Polytechnic University, Dalian 116034, China \\ ${ }^{2}$ School of Information Science and Engineering, Dalian Polytechnic University, Dalian 116034, China \\ Correspondence should be addressed to Desheng Li; deshengli80@yahoo.com and Hai Lin; lhai@dlpu.edu.cn \\ Received 19 November 2018; Revised 18 March 2019; Accepted 31 March 2019; Published 5 May 2019 \\ Academic Editor: Marco Cannas \\ Copyright (c) 2019 Zhimin Yu et al. This is an open access article distributed under the Creative Commons Attribution License, \\ which permits unrestricted use, distribution, and reproduction in any medium, provided the original work is properly cited. \\ Intense reddish-orange fluorescence of $\mathrm{Eu}^{3+}$ is observed in multiligand europium complexes $\mathrm{Eu}(\mathrm{BA})(\mathrm{TTA})_{2}$ and $\mathrm{Eu}(\mathrm{BA})(\mathrm{T}$ - \\ TA $)_{2}$ Phen doped polyvinylpyrrolidone (PVP). Under $367 \mathrm{~nm}$ UVA-LED pumping with $708.5 \mu \mathrm{W}$, the net emission powers are as \\ high as 204.8 and $243.2 \mu \mathrm{W}$, and the total emission photon numbers are derived to be $635.9 \times 10^{12}$ and $754.9 \times 10^{12} \mathrm{cps}$ for \\ $\mathrm{Eu}(\mathrm{BA})(\mathrm{TTA})_{2}$ and $\mathrm{Eu}(\mathrm{BA})(\mathrm{TTA})_{2}$ Phen doped PVP thin films, respectively. It is incredible that the quantum yield (QY) is up to \\ $57.87 \%$ in the former; furthermore, as the introduction of Phen, the QY of $\mathrm{Eu}^{3+}$ is increased to $62.03 \%$, verifying the effectiveness \\ of multiligands in photon conversion. Conclusive photon quantification and efficient fluorescence emission reveal the potential of \\ europium complexes/PVP as UV-visible conversion layers for enhanced solar cells.
}

\section{Introduction}

Energy harvesting by means of the photovoltaic system has attracted extensive attention, while the inadequate utilization of ultraviolet (UV) radiation restricts application and development for solar cells [1-3]. In order to solve this problem, the photoluminescence materials are introduced into solar cells as photonic conversion layers [4-10]. As is well known, the fluorescent materials are able to absorb the short-wavelength photons and convert them into longwavelength photons with better spectral responsiveness for solar cells [11-13]. Proceeding from this angle, rare-earth europium complexes can be introduced into solar cells with a significant impact on the photoelectric conversion efficiency [14-17]. Consequently, the optical conversion materials are capable of absorbing UV radiation effectively, which are worthy of further research and development.

Compared to other photoluminescence materials, rareearth complexes have high fluorescence quantum efficiency and extremely narrow emission bands [18-20]. Moreover, the fluorescence of rare-earth complexes can be enhanced by synthesizing a stable complex with a suitable organic ligand. In the rare-earth organic complexes, the composite of $\beta$-diketone and carboxyl possesses better stability and higher fluorescence efficiency than those of single-ligand complexes [21-23]. Furthermore, the combination of europium complexes and organic polymers has good thermal properties, which is favorable in solar cells [24-27]. Herein, as a typical amphiprotic organic polymer, polyvinylpyrrolidone (PVP) is introduced into rare-earth complexes with low toxicity, excellent chemical stability, and good compatibility [28-31]. Hence, europium complexes/PVP as the emitters in organic photoluminescence devices is a potential candidate as an UV-visible conversion layer for enhanced solar cells, and the schematic diagram is proposed and depicted in Figure 1.

In this work, the europium complexes/PVP luminescence films with high absorption efficiency and intense fluorescence emission have been synthesized. The brilliant reddish-orange fluorescence indicates the validity of energy transfer from multiligands to $\mathrm{Eu}^{3+}$ through intramolecular energy transfer. Under UVA-LED radiation, the absorption and emission photon numbers are obtained, and the quantum yields are estimated as high as $57.87 \%$ and $62.03 \%$ for $\mathrm{Eu}(\mathrm{BA})(\mathrm{TTA})_{2} / \mathrm{PVP}$ and $\mathrm{Eu}(\mathrm{BA})(\mathrm{TTA})_{2} \mathrm{Phen} / \mathrm{PVP}$, respectively. The multiligand europium complexes doped PVP thin film protects the solar cells components on the one hand 


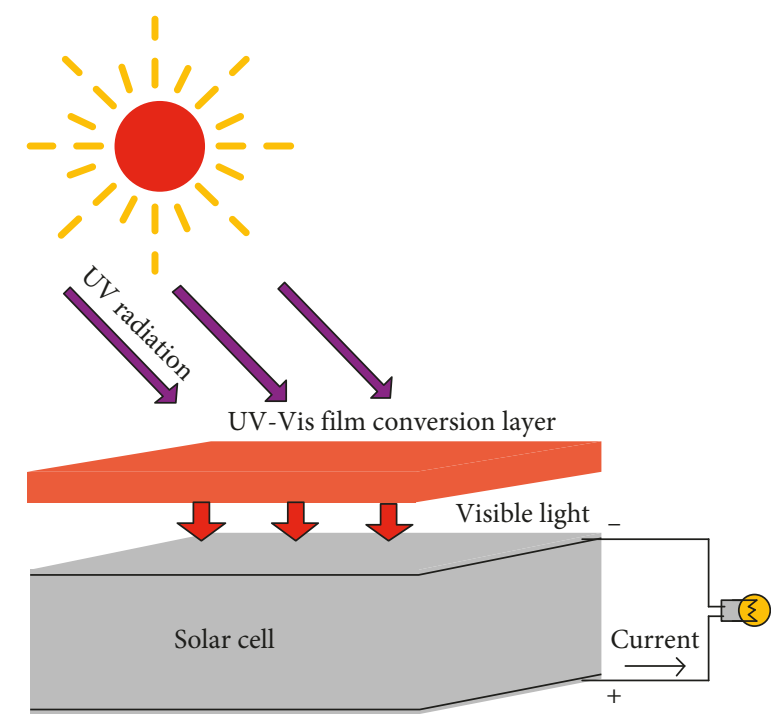

FIgURE 1: Schematic diagram of UV-visible conversion layer for enhanced solar cells.

and improves the photon conversion efficiency on the other hand, which is prospective as UV-visible conversion layers for enhanced solar cells.

\section{Experimental}

Ternary complex $\mathrm{Eu}(\mathrm{BA})(\mathrm{TTA})_{2}$ and quaternary complex $\mathrm{Eu}(\mathrm{BA})(\mathrm{TTA})_{2}$ Phen were prepared by the chemical synthesis using benzoic acid (BA), thenoyltrifluoroacetone (TTA), and 1,10-phenanthroline (Phen). For example, according to $\mathrm{Eu}(\mathrm{BA})(\mathrm{TTA})_{2}$ Phen chemical formula, initially, $\mathrm{EuCl}_{3}, \mathrm{BA}$, TTA, and Phen with the molar ratio of $1: 1: 2: 1$ were dissolved in $30 \mathrm{ml} 99.7 \%$ ethanol and placed in a water bath at $50^{\circ} \mathrm{C}$, and then, sodium hydroxide $(\mathrm{NaOH})$ solution was dripped to the $\mathrm{pH}$ value of 6-7. Instantaneously, the white precipitate of $\mathrm{Eu}(\mathrm{BA})(\mathrm{TTA})_{2}$ Phen was formed, which was filtered, washed, and dried at room temperature. In the fabrication process of europium complexes doped PVP, $1 \mathrm{~g}$ PVP powder was dissolved in $0.95 \mathrm{~g} \mathrm{~N}, \mathrm{~N}$-dimethylformamide (DMF) solution and $10 \mathrm{ml}$ ethyl alcohol solution followed by the addition of $0.01 \mathrm{~g} \mathrm{Eu(BA)(TTA)})_{2}$ and $0.01 \mathrm{~g} \mathrm{Eu}(\mathrm{BA})(\mathrm{T}$ $\mathrm{TA})_{2}$ Phen, respectively. The well-mixed solutions were heated at $50^{\circ} \mathrm{C}$ for 1 hour using a thermostat water bath, and the samples were obtained by evaporating the solvent slowly. Finally, the resultant solution was deposited on the quartz sheet and dried to obtain transparent films.

Fourier-transform infrared (FT-IR) spectra were measured at room temperature by a PerkinElmer FT-IR/NIR spectrometer in the range of $4000-400 \mathrm{~cm}^{-1}$. The elemental analysis was carried out by energy dispersive X-ray spectroscopy (EDS) at an accelerating voltage of $5 \mathrm{kV}$. The emission and excitation spectra were taken on a Hitachi F-7000 fluorescence spectrophotometer equipped with a photomultiplier tube (PMT) as a detector and a commercial CW Xe-lamp as a pump source. Transmittance spectra were recorded by a UV-1600 spectrophotometer. The differential scanning calorimetry (DSC) and the thermogravimetric analysis (TGA) were carried out by the American TA company SDT 600 at a heating rate of $20^{\circ} \mathrm{C} / \mathrm{min}$ under a dynamic nitrogen atmosphere. By the Metricon 2010 prism coupler, the refractive indices of the $\mathrm{Eu}(\mathrm{BA})(\mathrm{TTA})_{2}$ and $\mathrm{Eu}(\mathrm{BA})(\mathrm{TTA})_{2}$ Phen doped PVP were measured to be 1.5215 and 1.5256 at $635.96 \mathrm{~nm}$, and 1.5091 and 1.5115 at $1546.9 \mathrm{~nm}$, respectively. The refractive indices of other wavelengths can be reckoned by Cauchy equation $n=(A+$ $B) / \lambda^{2}$ with $A=1.5066$ and $B=6035.2 \mathrm{~nm}^{2}$ for Eu(BA)(TTA) $)_{2}$ doped PVP, and $A^{\prime}=1.5086$ and $B^{\prime}=6862.6 \mathrm{~nm}^{2}$ for $\mathrm{Eu}(\mathrm{BA})(\mathrm{TTA})_{2}$ Phen doped PVP. All of the spectral power distributions of $\mathrm{Eu}(\mathrm{BA})(\mathrm{TTA})_{2} / \mathrm{PVP}$ and $\mathrm{Eu}(\mathrm{BA})(\mathrm{TTA})_{2-}$ Phen/PVP were carried out in an integrating sphere of $25 \mathrm{~cm}$ inner diameter (Labsphere) which was connected to a QE65000 and a USB4000 standard CCD detector (Ocean Optics) with a $600 \mu \mathrm{m}$-core optical fiber. The currents of the exciting $308 \mathrm{~nm}$ UVB and $367 \mathrm{~nm}$ UVA light emitting diode were fixed at $20 \mathrm{~mA}$ with reference voltages 5.780 and $3.607 \mathrm{~V}$, respectively. The samples covered the upper part of LED completely, and the measurement system is calibrated with a standard halogen lamp (Labsphere, SCL-050).

\section{Results and Discussion}

3.1. Structural Analysis of Multiligand Europium Complexes. The structures of $\mathrm{Eu}(\mathrm{BA})(\mathrm{TTA})_{2}, \mathrm{Eu}(\mathrm{BA})(\mathrm{TTA})_{2}$ Phen, $\mathrm{Eu}(\mathrm{BA})(\mathrm{TTA})_{2} / \mathrm{PVP}, \mathrm{Eu}(\mathrm{BA})(\mathrm{TTA})_{2} \mathrm{Phen} / \mathrm{PVP}$, and PVP are measured in the $4000-400 \mathrm{~cm}^{-1}$ region by FT-IR spectroscopy, as shown in Figure 2. Such as the case of $\mathrm{Eu}(\mathrm{BA})(\mathrm{TTA})_{2}$ Phen (curve 2), after the coordination formation between organic ligand and $\mathrm{Eu}^{3+}$, the carbonyl group $(-\mathrm{C}=\mathrm{O})$ stretching vibration absorption peak of TTA has a redshift from 1680 to $1605 \mathrm{~cm}^{-1}$ [32,33], which is caused by the reduction of bond length and bond energy of the covalent bond because the isolated electrons transfer from part of the oxygen to the outer layer of a hollow orbit in $\mathrm{Eu}^{3+}$. In addition, carbonyl is conjugated with $\mathrm{Eu}^{3+}$ after the deprotonation, subsequently forming a stable chelating ring, and then the conjugate effect of the system makes the density of $\pi$-electron cloud more uniform; therefore, absorption frequency is decreased, and polarity of the covalent bonds is weakened [34, 35]. The peaks located in the range of 1304-1357 and $1538-1569 \mathrm{~cm}^{-1}$ belong to symmetric and antisymmetric stretching vibrations of carboxyl, respectively, indicating the carboxylic acid of BA removes the proton and coordinates with the $\mathrm{Eu}^{3+}$ ions. Compared with $\mathrm{Eu}(\mathrm{BA})(\mathrm{TTA})_{2}$ (curve 1), the absorption peak shifts from 1545 to $1538 \mathrm{~cm}^{-1}$ due to the introduction of the third ligand suggesting the energy required for vibration is higher, and the group is more stable. And the noncharacteristic absorption $\mathrm{C}=\mathrm{N}$ stretching vibration peak of Phen appears a slight redshift from 1422 to $1415 \mathrm{~cm}^{-1}$, demonstrating that the lone pair of electrons on the two $\mathrm{N}$ atoms of the Phen coordinates with the $\mathrm{Eu}^{3+}$ to form the chelate ring [33]. Moreover, the spectra of PVP-loaded composite films have changed significantly in contrast to powders, and the corresponding absorption peaks of the complex powders are weakened due to the overlapping of PVP vibration peaks. Besides, the blue shift of $\mathrm{C}=\mathrm{O}$ stretching vibration in $\mathrm{Eu}(\mathrm{BA})(\mathrm{TTA})_{2} / \mathrm{PVP}\left(1660 \mathrm{~cm}^{-1}\right)$ and $\mathrm{Eu}(\mathrm{BA})(\mathrm{TTA})_{2} \mathrm{Phen} /$ 


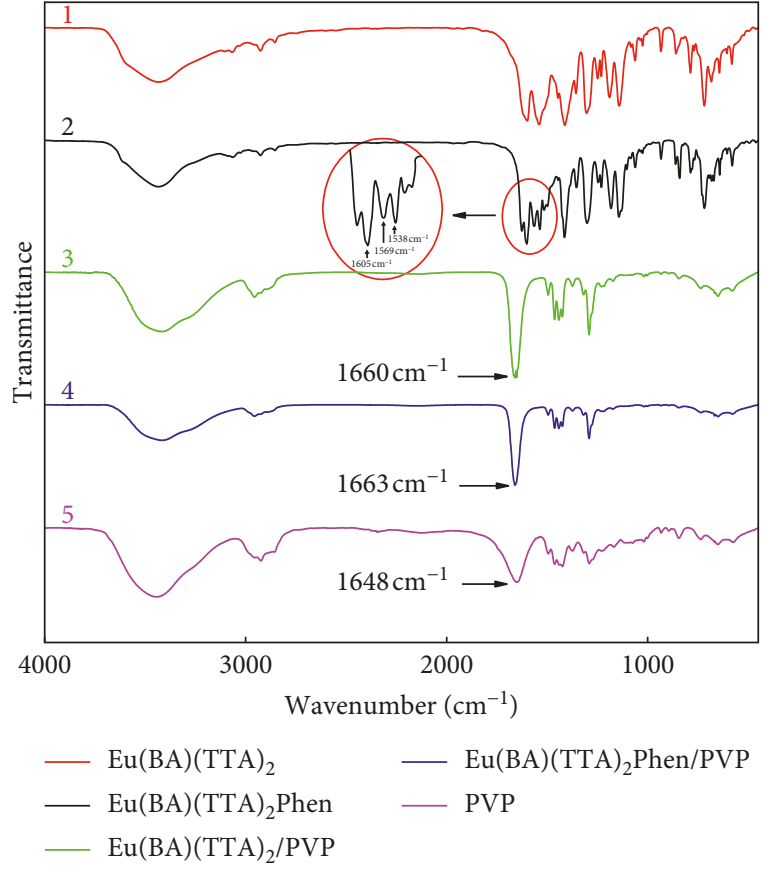

Figure 2: FT-IR spectra of Eu(BA)(TTA) 2 (curve 1), Eu(BA)(TTA) ${ }_{2}$ Phen (curve 2), Eu(BA)(TTA) ${ }_{2} /$ PVP (curve 3), Eu(BA)(TTA) ${ }_{2}$ Phen/PVP (curve 4), and PVP (curve 5), respectively.

PVP $\left(1663 \mathrm{~cm}^{-1}\right)$ occurs remarkably in contrast to purephased PVP $\left(1648 \mathrm{~cm}^{-1}\right)$, which further confirms the effects of dopants on the FT-IR spectra of PVP.

For the sake of examining the elemental composition in the films, the EDS spectra of $\mathrm{Eu}(\mathrm{BA})(\mathrm{TTA})_{2} / \mathrm{PVP}$ and $\mathrm{Eu}(\mathrm{BA})(\mathrm{TTA})_{2}$ Phen/PVP are obtained, as shown in Figures $3(\mathrm{a})$ and $3(\mathrm{~b})$, respectively. Both of them show that the $\mathrm{C}, \mathrm{O}, \mathrm{N}, \mathrm{Eu}, \mathrm{S}$, and $\mathrm{F}$ elements existed in europium complex originate from BA, TTA, and Phen ligands, which provides a basis for the synthesis of the europium complexes doped PVP composites. Meanwhile, the schematic diagram based on the molecular formula of $\mathrm{Eu}(\mathrm{BA})(\mathrm{TTA})_{2}$ and $\mathrm{Eu}(\mathrm{BA})(\mathrm{TTA})_{2}$ Phen is illustrated in Figure 3 . In $\mathrm{Eu}(\mathrm{BA})(\mathrm{TTA})_{2}$ Phen, the center $\mathrm{Eu}^{3+}$ connects to three ligands (BA, TTA, and Phen), among which Phen as a synergic shielding ligand enhances the luminescence intensity of the complexes $[36,37]$. The presence of the surrounding ligand acts as a physical buffer between the $\mathrm{Eu}^{3+}$ and other ions.

3.2. Fluorescence Behaviors of Multiligand Europium Complexes/PVP. Figures 4(a) and 4(b) show the emission spectra of $\mathrm{Eu}(\mathrm{BA})(\mathrm{TTA})_{2}$ and $\mathrm{Eu}(\mathrm{BA})(\mathrm{TTA})_{2}$ Phen powders under the excitation of 278 and $366 \mathrm{~nm}$, both of them exhibit the typical emission peaks of $\mathrm{Eu}^{3+}$ located at 578, 591, 615, 651, and $701 \mathrm{~nm}$, which are ascribed to the $\mathrm{Eu}^{3+}$ transitions from the ${ }^{5} D_{0}$ to ${ }^{7} F_{J}(J=0-4)[38,39]$, respectively. Among them, the ${ }^{5} D_{0} \longrightarrow{ }^{7} F_{2}$ electric dipole transition has the strongest relative fluorescence intensity, which reveals the better monochromaticity of europium complexes. The excitation spectra of multiligand europium complexes monitored at
$615 \mathrm{~nm}$ are depicted in Figure 4(c), and a broad band almost covers the whole ultraviolet region, which mainly corresponds to $\pi \longrightarrow \pi^{*}$ electronic transition of the ligands. Meanwhile, the excitation of coligand Phen exists in the long-wavelength region, indicating that the introduction of the Phen enlarges the range of conjugated $\pi \longrightarrow \pi^{*}$ and facilitates energy transfer.

In order to facilitate the application in solar cells, the preparation of $\mathrm{Eu}(\mathrm{BA})(\mathrm{TTA})_{2}$ and $\mathrm{Eu}(\mathrm{BA})(\mathrm{TTA})_{2}$ Phen doped PVP films is carried out, and the emission and excitation spectra are shown in Figure 5, respectively. The broad band from ligand at about $310 \mathrm{~nm}$ is mainly attributed to the transition of $\pi \longrightarrow \pi^{*}$ of the BA under $278 \mathrm{~nm}$ excitation. Simultaneously, the larger emission intensity of $\mathrm{Eu}(\mathrm{BA})(\mathrm{TTA})_{2} \mathrm{Phen} / \mathrm{PVP}$ at $366 \mathrm{~nm}$ can be explained in accordance with the introduction of Phen as a synergistic screening ligand for BA and TTA. Bright red fluorescence is observed, and the effect of Phen is reconfirmed upon enhanced emission, indicating the availability of conversion from UV to visible photons. Figure 5(c) reveals the excitation spectra of $\mathrm{Eu}(\mathrm{BA})(\mathrm{TTA})_{2} / \mathrm{PVP}$ and $\mathrm{Eu}(\mathrm{BA})(\mathrm{TTA})_{2}$ Phen/PVP by monitoring the ligand emission at $381 \mathrm{~nm}$, respectively. It can be effectively activated within the scope of 200-360 nm, and the optimum excitation wavelength locates at $278 \mathrm{~nm}$. As shown in Figure 5(d), an excited broad band of europium complexes/PVP in the UV region indicates the effective absorption of the organic ligands.

Taking an example of quaternary complex, in order to clearly show the crosslink interaction between the europium complexes and PVP, the normalized excitation spectra of $\mathrm{Eu}(\mathrm{BA})(\mathrm{TTA})_{2}$ Phen and Eu(BA)(TTA $)_{2}$ Phen/PVP monitored at $615 \mathrm{~nm}$ are depicted in Figure 6. It can be seen that the excitation peak located at $373 \mathrm{~nm}$ shows a slight blue shift and the width of excitation peak narrows in the $\mathrm{Eu}(\mathrm{BA})(\mathrm{TTA})_{2}$ Phen/PVP films. Moreover, the fluorescence intensity decreases significantly in the short-wavelength range, which indicates the strong interaction between PVP and rare-earth complex with the occurrence of energy transfer. Meanwhile, the two broad bands further confirm that both $\mathrm{Eu}(\mathrm{BA})(\mathrm{TTA})_{2} / \mathrm{PVP}$ and $\mathrm{Eu}(\mathrm{BA})(\mathrm{TTA})_{2} \mathrm{Phen} /$ PVP can be stimulated under the entire UV range, and the latter is more efficient. The reason for the intensity increment is that the cooperative ligand Phen improves the conjugation and the electron delocalization of the whole system, which facilitates the absorption and the utilization of UV radiation [40-42].

In rare-earth complexes, energy transfer efficiency mainly depends on the energy level matching between the excited state of rare-earth ions and the triplet state of the ligand, and the better the energy level matching, the stronger the fluorescence emitting [43]. The possible energy transfer mechanisms of $\mathrm{Eu}(\mathrm{BA})(\mathrm{TTA})_{2} / \mathrm{PVP}$ and $\mathrm{Eu}(\mathrm{BA})(\mathrm{TTA})_{2} \mathrm{Phen} / \mathrm{PVP}$ are portrayed in Figure 7 . In $\mathrm{Eu}(\mathrm{BA})(\mathrm{TTA})_{2} \mathrm{Phen} / \mathrm{PVP}$, the ligands absorb the energy from the ground state to the first two lowest energy singlet excited states $S_{0} \longrightarrow S_{1}$ and $S_{0} \longrightarrow S_{2}$ under 278 and $366 \mathrm{~nm}$ excitation. As shown in Figure 7(b), the energy flows from BA- $S_{1}$ to Phen- $S_{1}$, then to TTA- $S_{2}$, and internal conversion to TTA- $S_{1}$ under $278 \mathrm{~nm}$ excitation. Because the energy levels of Phen- $S_{1}$ and TTA- $S_{2}$ are close, the 


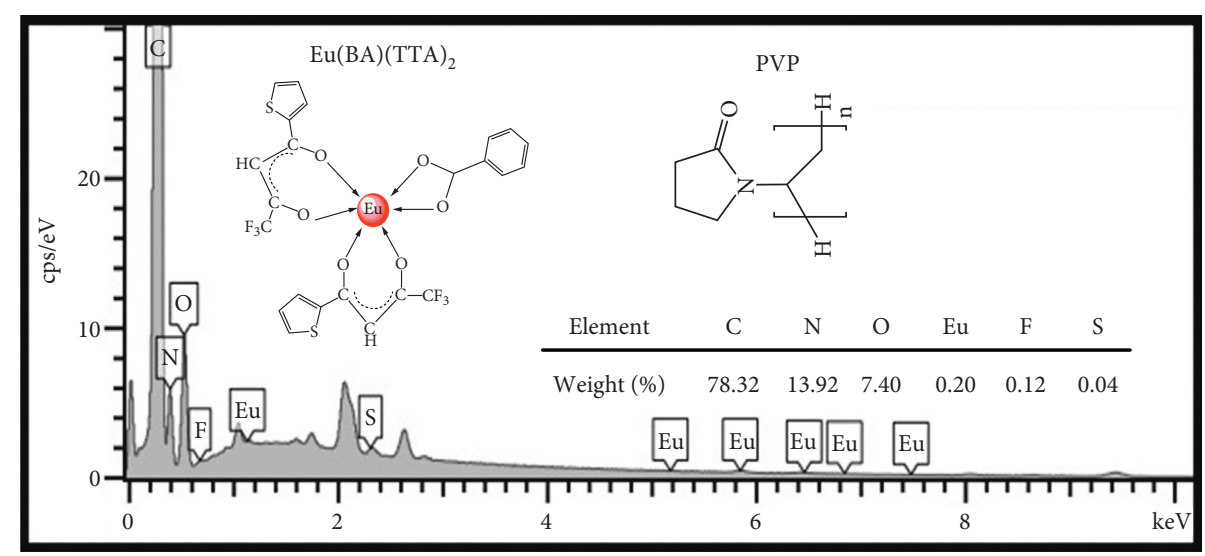

(a)

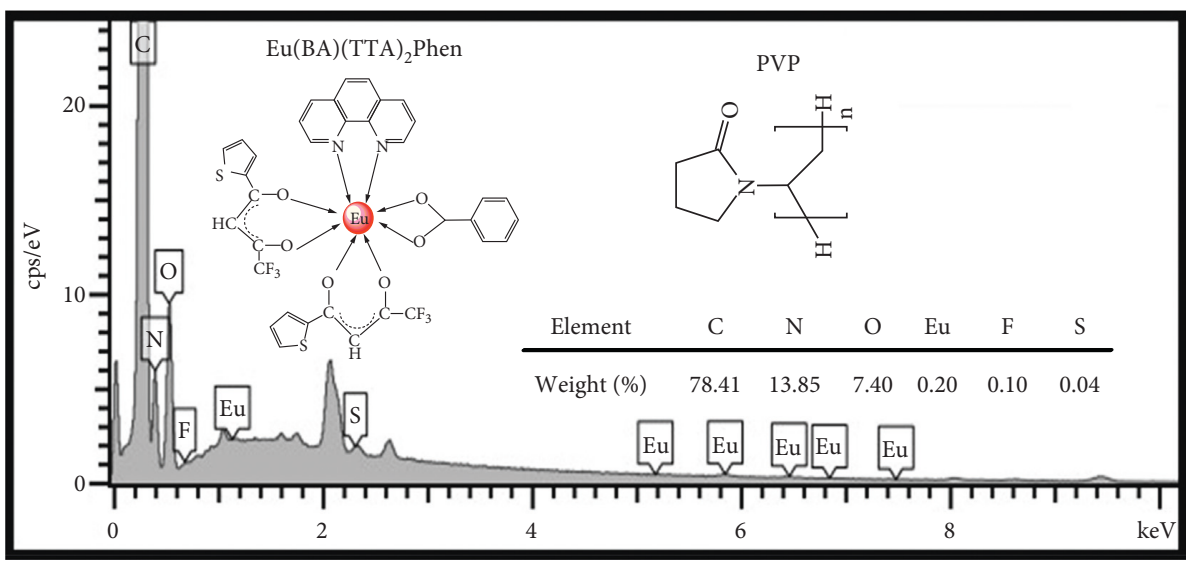

(b)

Figure 3: EDS spectra of Eu(BA)(TTA) $)_{2} /$ PVP (a) and Eu(BA)(TTA) $)_{2}$ Phen/PVP (b).

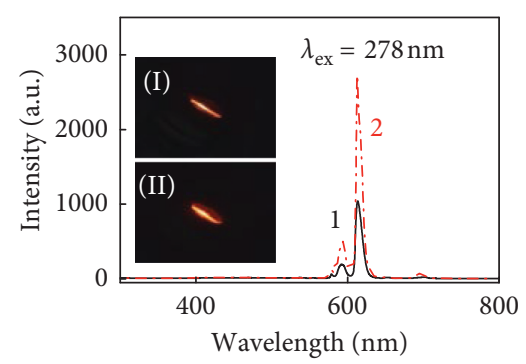

(a)

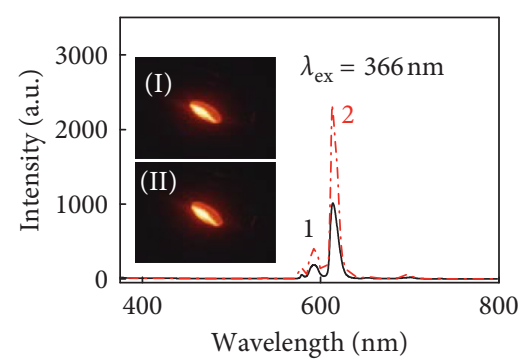

(b)

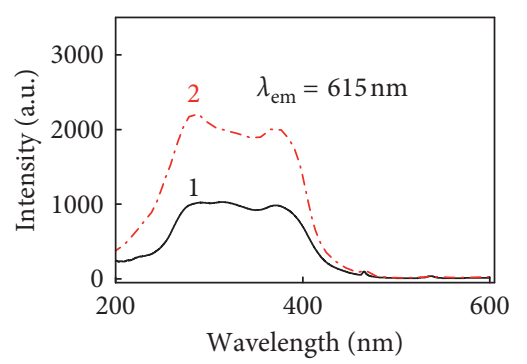

(c)

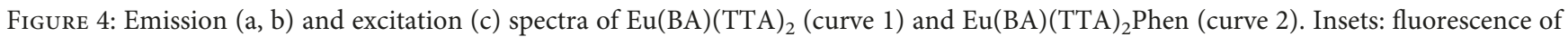
$\mathrm{Eu}(\mathrm{BA})(\mathrm{TTA})_{2}(\mathrm{I})$ and $\mathrm{Eu}(\mathrm{BA})(\mathrm{TTA})_{2}$ Phen (II), respectively.

resonance is allowed to transit from $S_{1}$ to $S_{2}$, and vice versa. Subsequently, partial energy of TTA is released in the form of fluorescence (FL), and the other is transferred to its triplet excited state through intersystem crossing (ISC) and then released FL. In addition, under the excitation of $366 \mathrm{~nm}$, TTA gets directly excited to $S_{1}$ due to changes in the circumstance, and some energy is transferred to TTA- $T_{1}$ through ISC and others to Phen- $T_{1}$. Finally, the energy transfers from the ligands to the resonantly excited level ${ }^{5} \mathrm{D}_{2}$ of $\mathrm{Eu}^{3+}$ ion $[11,44-48]$. The ${ }^{5} D_{0}$ level is populated by the nonradiative relaxation (NRR); afterward, the radiative transition takes place accompanying the release of visible emissions.
3.3. Absolute Spectra and Radiometric Flux Quantitation. To accurately reflect the fluorescence performance of multiligand europium complexes/PVP thin films, the absolute spectral parameters were determined which provides an external quantum yield to assess luminescence and laser materials. Spectral power distributions of $\operatorname{Eu}(\mathrm{BA})(\mathrm{TTA})_{2} /$ PVP and $\mathrm{Eu}(\mathrm{BA})(\mathrm{TTA})_{2}$ Phen/PVP are recorded using an integrating sphere with a $367 \mathrm{~nm}$ UVA-LED as the pump source when the sample on the quartz sheet is located on the top of the LED pump source. By removing the influence of the quartz sheet, the net spectral power distributions of europium complexes/PVP are obtained, as depicted in 


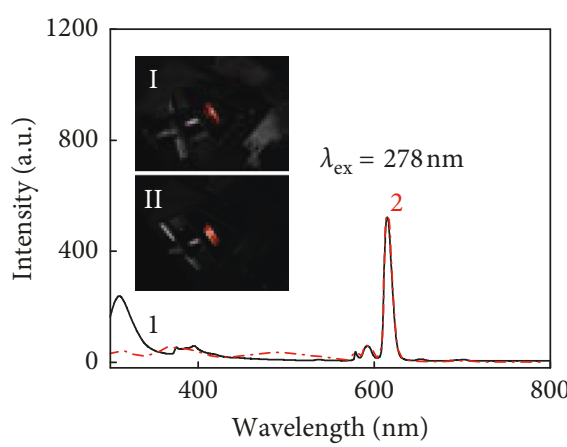

(a)

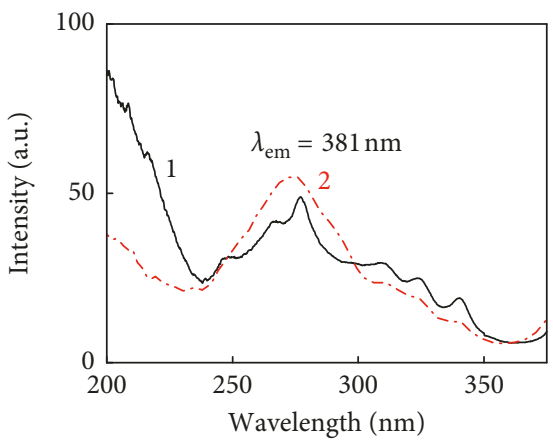

(c)

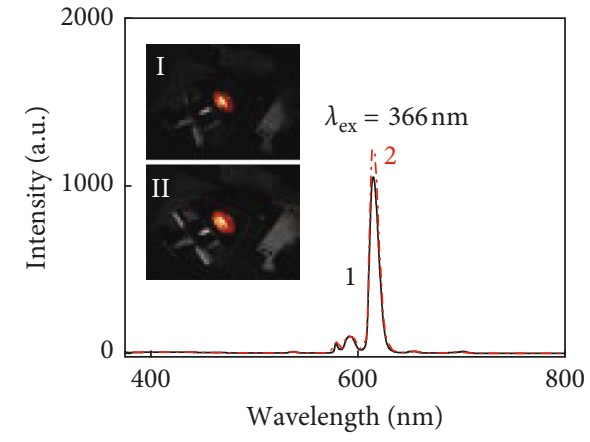

(b)

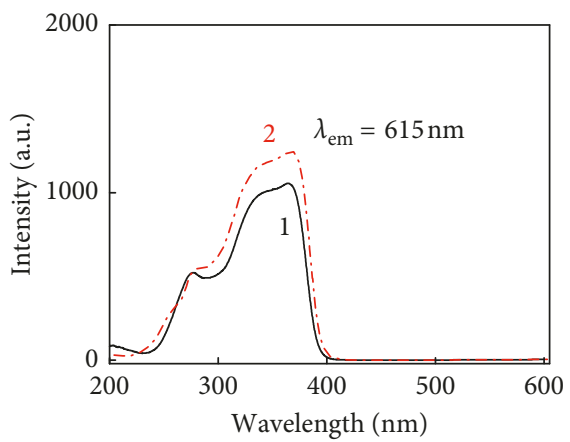

(d)

Figure 5: Emission (a, b) and excitation (c, d) spectra of Eu(BA)(TTA) 2 /PVP (curve 1) and Eu(BA)(TTA) 2 Phen/PVP (curve 2). Insets: fluorescence of $\mathrm{Eu}(\mathrm{BA})(\mathrm{TTA})_{2} / \mathrm{PVP}$ (I) and $\mathrm{Eu}(\mathrm{BA})(\mathrm{TTA})_{2} \mathrm{Phen} / \mathrm{PVP}$ (II), respectively.

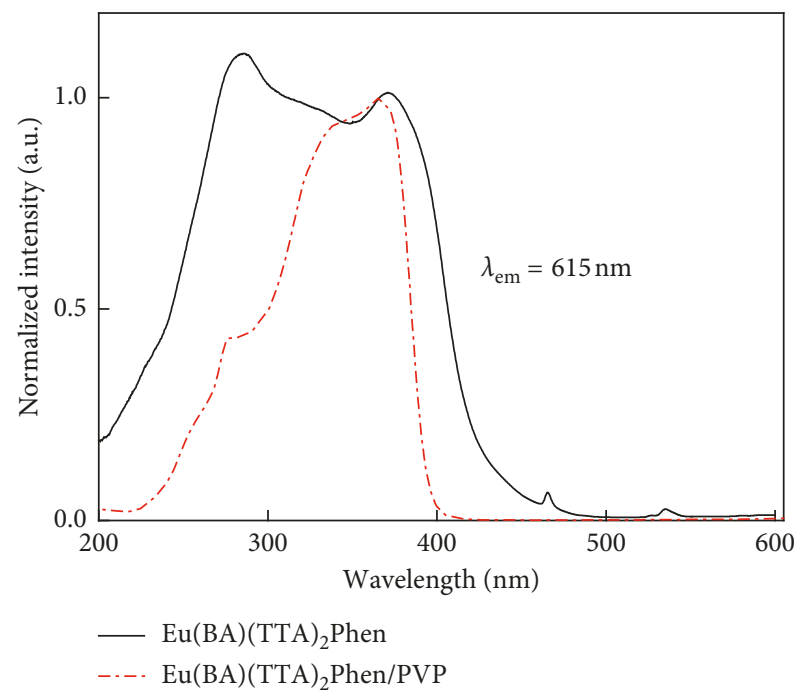

Figure 6: Normalized excitation spectra of Eu(BA)(TTA) $)_{2}$ Phen and $\mathrm{Eu}(\mathrm{BA})(\mathrm{TTA})_{2}$ Phen/PVP.

Figure 8 , and the net emission powers are calculated to 204.8 and $243.2 \mu \mathrm{W}$, respectively. Subsequently, the bright reddish-orange fluorescence is observed, and the CIE coordinates of $\mathrm{Eu}(\mathrm{BA})(\mathrm{TTA})_{2} / \mathrm{PVP}$ and $\mathrm{Eu}(\mathrm{BA})(\mathrm{TTA})_{2} \mathrm{Phen} /$ PVP are calculated to $(0.670,0.330)$ and $(0.671,0.329)$, respectively, verifying the effectiveness of multiligands in photon conversion and providing the theoretical basis for the application in enhanced solar cells.
The photon distribution provides the fundamental information in optical field and relevant applications. Based on the net spectral power distributions, the photon distributions can be derived by

$$
N(v)=\frac{\lambda^{3}}{h c} P(\lambda),
$$

where $v, \lambda, h, c$, and $P(\lambda)$ represent wavenumber, wavelength, Planck constant, vacuum light velocity and spectral power distribution, respectively. The net absorption and emission photon distributions of $\mathrm{Eu}(\mathrm{BA})(\mathrm{TTA})_{2} / \mathrm{PVP}$ and $\mathrm{Eu}(\mathrm{BA})(\mathrm{TTA})_{2} \mathrm{Phen} / \mathrm{PVP}$ are calculated by equation (1) and depicted in Figure 9, and the integrated values are listed in Table 1. Meanwhile, the total emission photon numbers are derived to be $635.9 \times 10^{12}$ and $754.9 \times 10^{12} \mathrm{cps}$ for $\mathrm{Eu}(\mathrm{BA})(\mathrm{TTA})_{2}$ and $\mathrm{Eu}(\mathrm{BA})(\mathrm{TTA})_{2}$ Phen doped PVP thin films, respectively.

Quantum yield (QY) is used to reflect the utilization of luminescent materials to the absorption of photons and is defined as the photon number ratio of emission and absorption [49]. Namely,

$$
\mathrm{QY}=\frac{\text { emitted photons }}{\text { absorbed photons }}=\frac{\mathrm{N}_{\mathrm{em}}}{\mathrm{N}_{\mathrm{abs}}} .
$$

All the QY values for different emission peaks of europium complexes/PVP under the excitation of the $367 \mathrm{~nm}$ UVA-LED are listed in Table 1. The total QYs of $\mathrm{Eu}(\mathrm{BA})(\mathrm{TTA})_{2} / \mathrm{PVP}$ and $\mathrm{Eu}(\mathrm{BA})(\mathrm{TTA})_{2} \mathrm{Phen} / \mathrm{PVP}$ are derived to be $57.87 \%$ and $62.03 \%$, respectively, which are far 


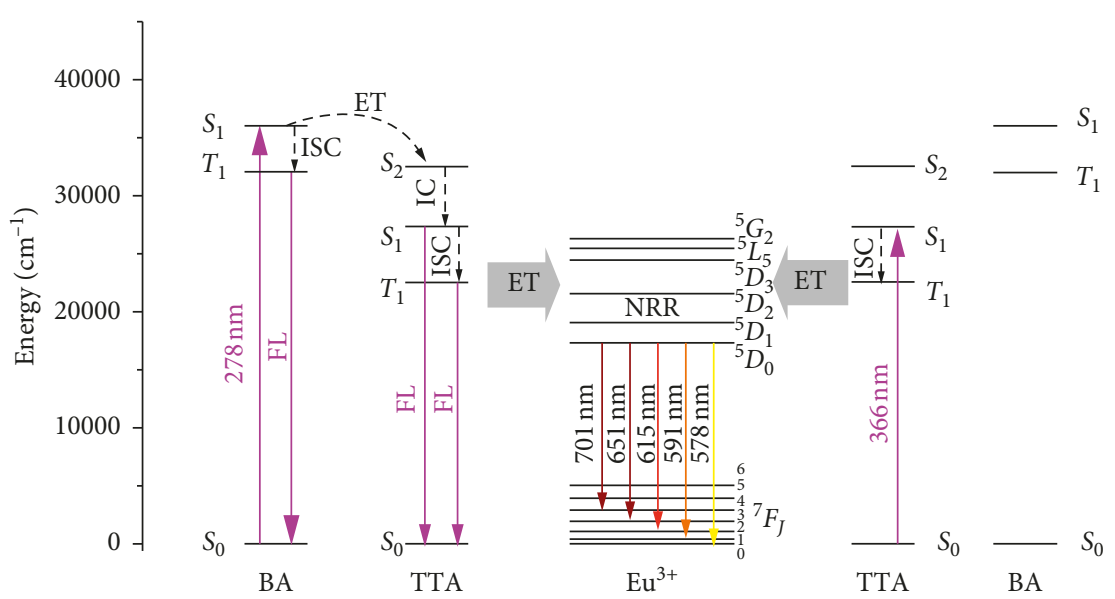

(a)

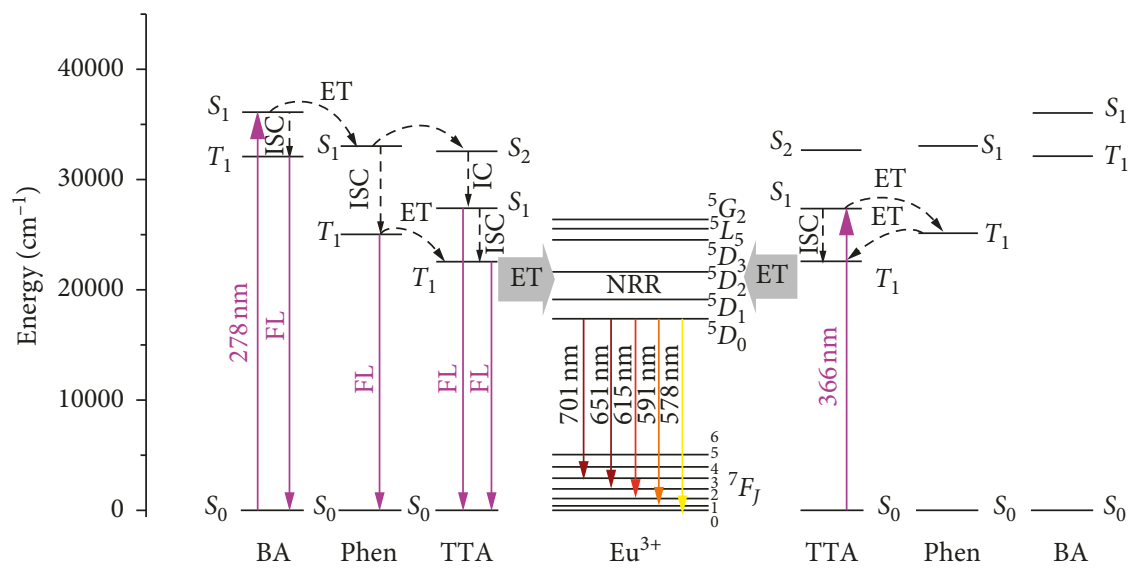

(b)

Figure 7: Schematic energy level diagram: energy transfer processes and different transitions in $\operatorname{Eu}(\mathrm{BA})(\mathrm{TTA})_{2} / \mathrm{PVP}$ (a) and $\mathrm{Eu}(\mathrm{BA})(\mathrm{TTA})_{2}$ Phen/PVP (b). ISC, intersystem crossing, IC, internal conversion, ET, energy transfer, S, singlet, T, triplet, and NRR, nonradiative relaxation.

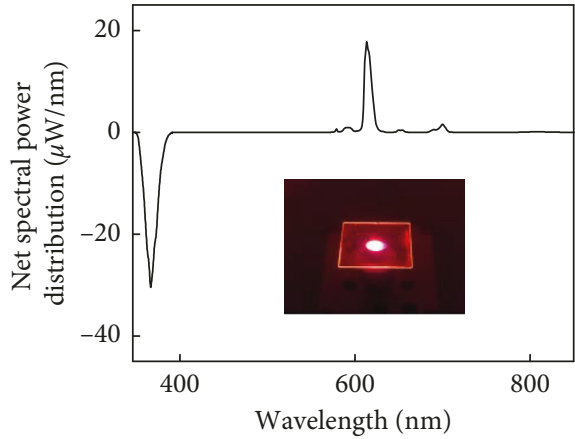

(a)

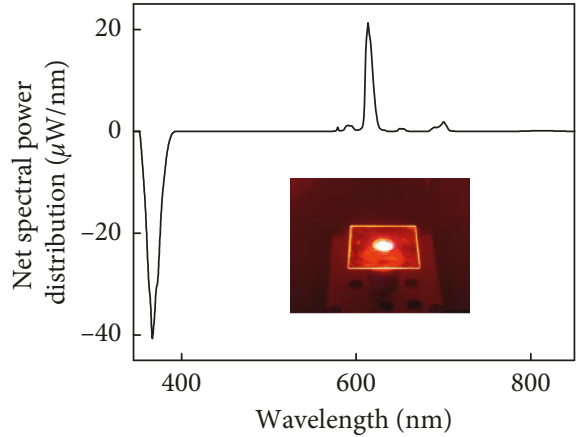

(b)

Figure 8: Net spectral power distributions of Eu(BA)(TTA) $)_{2} / \mathrm{PVP}$ (a) and Eu(BA)(TTA) 2 Phen/PVP (b) under 367 nm UVA-LED excitation. Insets: fluorescence of $\mathrm{Eu}(\mathrm{BA})(\mathrm{TTA})_{2} / \mathrm{PVP}$ (a) and $\mathrm{Eu}(\mathrm{BA})(\mathrm{TTA})_{2} \mathrm{Phen} / \mathrm{PVP}(\mathrm{b})$ in an integrating sphere under $367 \mathrm{~nm}$ UVA-LED excitation.

higher than those of $9.34 \%$ in Eu(DBM) ${ }_{3}$ Phen/PMMA [50], $18 \%$ in $\mathrm{Eu}(\mathrm{DBM})_{3} \mathrm{PIP} / \mathrm{PVP}$ [51], and $36 \% \mathrm{Eu}(\mathrm{DBM}-$ D) ${ }_{3}$ (Bath)/PMMA [52]. The large QYs reflect the effectiveness of the photon utilization in the multiligand europium complexes. In the table, the absolute quantum efficiency is accordingly changed with the introduction of Phen. Due to the low inversion symmetry at $\mathrm{Eu}^{3+}$ ion sites, the mixture of uneven ligand field components and the electric dipole transitions is no longer strictly forbidden in the ligand fields, resulting in faster electron transition radiation rates. 


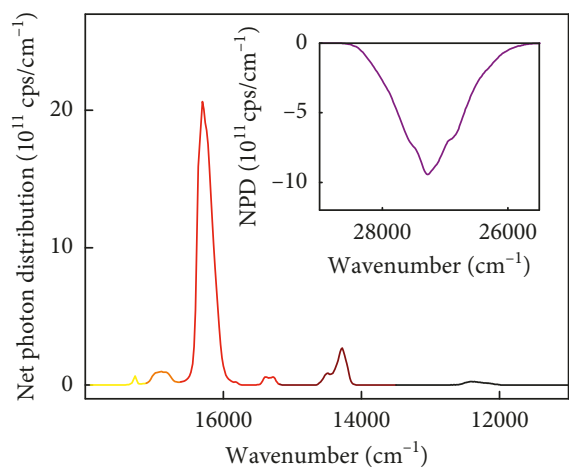

(a)

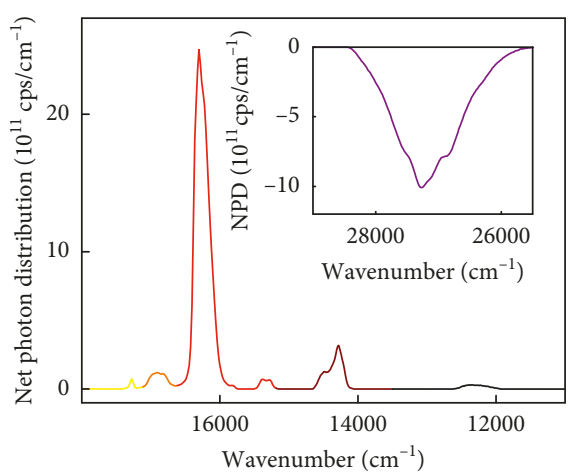

(b)

Figure 9: Net photon distributions of $\mathrm{Eu}(\mathrm{BA})(\mathrm{TTA})_{2} / \mathrm{PVP}$ (a) and $\mathrm{Eu}(\mathrm{BA})(\mathrm{TTA})_{2}$ Phen/PVP (b) under 367 nm UVA-LED excitation. Insets: details of the absorption photon distributions.

TABle 1: Absorption, emission photon number, and quantum yield in Eu(BA)(TTA) $2 / \mathrm{PVP}$ and Eu(BA)(TTA) ${ }_{2}$ Phen/PVP fibers under $367 \mathrm{~nm}$ UVA-LED excitation.

\begin{tabular}{|c|c|c|c|c|c|c|}
\hline Samples & $\begin{array}{l}\text { Absorption photon } \\
\text { number }\left(10^{14} \mathrm{cps}\right)\end{array}$ & $\begin{array}{l}\text { Emission } \\
\text { transition }\end{array}$ & $\begin{array}{c}\text { Wavenumber } \\
\left(\mathrm{cm}^{-1}\right)\end{array}$ & $\begin{array}{l}\text { Emission photon } \\
\text { number }\left(10^{12} \mathrm{cps}\right)\end{array}$ & $\begin{array}{l}\text { Quantum } \\
\text { yield (\%) }\end{array}$ & $\begin{array}{l}\text { Total quantum } \\
\text { yield (\%) }\end{array}$ \\
\hline $\mathrm{Eu}(\mathrm{BA})(\mathrm{TTA})_{2} / \mathrm{PVP}$ & 10.988 & $\begin{array}{l}{ }^{5} D_{0} \longrightarrow{ }^{7} F_{0} \\
{ }^{5} D_{0} \longrightarrow{ }^{7} F_{1} \\
{ }^{5} D_{0} \longrightarrow{ }^{7} F_{2} \\
{ }^{5} D_{0} \longrightarrow{ }^{7} F_{3} \\
{ }^{5} D_{0} \longrightarrow{ }^{7} F_{4} \\
{ }^{5} D_{0} \longrightarrow{ }^{7} F_{6}\end{array}$ & $\begin{array}{l}17276 \\
16894 \\
16301 \\
15379 \\
14275 \\
12416 \\
\end{array}$ & $\begin{array}{c}3.674 \\
33.021 \\
520.958 \\
11.985 \\
56.805 \\
9.480 \\
\end{array}$ & $\begin{array}{c}0.33 \\
3.01 \\
47.41 \\
1.09 \\
5.17 \\
0.86 \\
\end{array}$ & 57.87 \\
\hline $\begin{array}{l}\mathrm{Eu}(\mathrm{BA})(\mathrm{TTA})_{2} \mathrm{Phen} / \\
\mathrm{PVP}\end{array}$ & 12.168 & $\begin{array}{l}{ }^{5} D_{0} \longrightarrow{ }^{7} F_{0} \\
{ }^{5} D_{0} \longrightarrow{ }^{7} F_{1} \\
{ }^{5} D_{0} \longrightarrow{ }^{7} F_{2} \\
{ }^{5} D_{0} \longrightarrow{ }^{7} F_{3} \\
{ }^{5} D_{0} \longrightarrow{ }^{7} F_{4} \\
{ }^{5} D_{0} \longrightarrow{ }^{7} F_{6}\end{array}$ & $\begin{array}{l}17276 \\
16916 \\
16301 \\
15379 \\
14275 \\
12336\end{array}$ & $\begin{array}{c}4.217 \\
39.581 \\
611.108 \\
13.809 \\
73.404 \\
12.753\end{array}$ & $\begin{array}{c}0.35 \\
3.25 \\
50.22 \\
1.13 \\
6.03 \\
1.05\end{array}$ & 62.03 \\
\hline
\end{tabular}

Luminous flux refers to the amount of radiant flux that is evaluated according to the international standard of human visual characteristics [53]. The total luminous flux $\Phi_{\mathrm{V}}$ of the luminescence can be calculated by

$$
\Phi_{\mathrm{V}}=K_{\mathrm{m}} \int_{380}^{780} V(\lambda) P(\lambda) d \lambda,
$$

where $V(\lambda)$ is the relative eye sensitivity and $K_{\mathrm{m}}$ is the maximum luminous efficacy at $555 \mathrm{~nm}(683 \mathrm{~lm} / \mathrm{W})$. The luminous efficacy is obtained by dividing total luminous flux $\Phi_{\mathrm{V}}$ by the electric power (W) on the LED. Thereupon, the luminous flux distributions of the $\mathrm{Eu}(\mathrm{BA})(\mathrm{TTA})_{2} / \mathrm{PVP}$ and $\mathrm{Eu}(\mathrm{BA})(\mathrm{TTA})_{2}$ Phen/PVP films can be obtained under the excitations of $308 \mathrm{~nm}$ UVB-LED and $367 \mathrm{~nm}$ UVA-LED, as presented in Figure 10, and the relevant total luminous fluxes $\Phi_{\mathrm{V}}$ and luminous efficacy in the whole visible spectral region are listed in Table 2.

Under the excitation electric power of $115.61 \mathrm{~mW}$ for $308 \mathrm{~nm}$ UVB-LED, the total luminous fluxes $\Phi_{\mathrm{V}}$ of $\mathrm{Eu}(\mathrm{BA})(\mathrm{TTA})_{2} / \mathrm{PVP}$ and $\mathrm{Eu}(\mathrm{BA})(\mathrm{TTA})_{2}$ Phen/PVP are integrated to be 13.20 and $16.60 \mathrm{mlm}$ by equation (3) and luminous efficacy get $11.4 \%$ and $14.4 \% \mathrm{~lm} / \mathrm{W}$, respectively, which are higher than $2.63 \mathrm{mlm}$ and $2.27 \% \mathrm{~lm} / \mathrm{W}$ in TAH/ PMMA [54]. Under the excitation electric power of $72.14 \mathrm{~mW}$ for $367 \mathrm{~nm}$ UVA-LED, the luminous fluxes of residual LEDs are $0.33 \times 10^{-2}$ and $0.25 \times 10^{-2} \mathrm{mlm}$, and its role is negligible in $\mathrm{Eu}(\mathrm{BA})(\mathrm{TTA})_{2} / \mathrm{PVP}$ and $\mathrm{Eu}(\mathrm{BA})(\mathrm{TTA})_{2} \mathrm{Phen} / \mathrm{PVP}$, respectively. The total luminous fluxes of $\mathrm{Eu}(\mathrm{BA})(\mathrm{TTA})_{2} / \mathrm{PVP}$ and $\mathrm{Eu}(\mathrm{BA})(\mathrm{TTA})_{2} \mathrm{Phen} / \mathrm{PVP}$ are as high as 44.55 and $52.34 \mathrm{mlm}$, and luminous efficacy are calculated to $61.8 \%$ and $72.6 \% \mathrm{~lm} / \mathrm{W}$ when excited by $367 \mathrm{~nm}$ UVA-LED, respectively. As the excitation wavelength changes, both of luminous flux values and luminous efficacy show upward tendency due to the enhancement of conversion fluorescence intensity. Moreover, the $367 \mathrm{~nm}$ UVA-LED is confirmed as a more effective excitation device for the sample, and the higher luminous efficacy reveals that the multiligand europium complexes have good luminescence ability under UV radiation.

Judd-Ofelt (J-O) intensity parameters $\Omega_{t}(t=2,4,6)$ are used to evaluate rare-arth ion interaction with the substrate, which reflect some characteristics of the local coordination field and estimate the population of odd parity electron transitions $[55,56]$. Since the $\mathrm{Eu}^{3+}$ has limited absorption transitions and the special energy level structure, radiative transition properties of $\mathrm{Eu}^{3+}$ in $\mathrm{Eu}(\mathrm{BA})(\mathrm{TTA})_{2} / \mathrm{PVP}$ and $\mathrm{Eu}(\mathrm{BA})(\mathrm{TTA})_{2} \mathrm{Phen} / \mathrm{PVP}$ are derived from their emission behaviors [57]. The $\Omega_{t}(t=2,4$, and 6) are determined based on emission photon numbers and listed in Table 3 , and the 


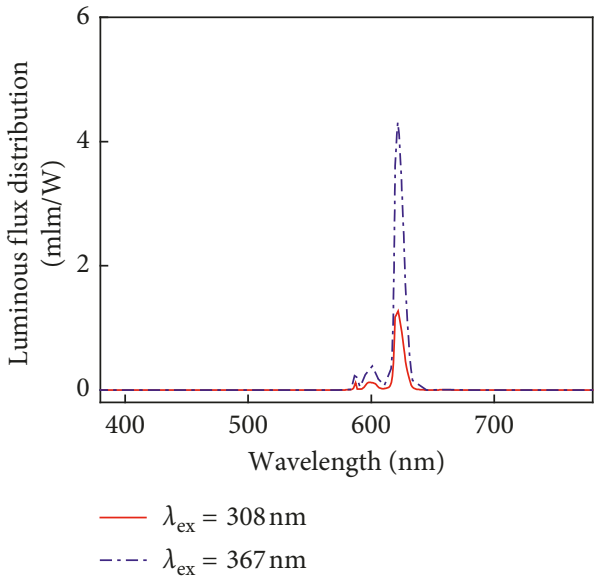

(a)

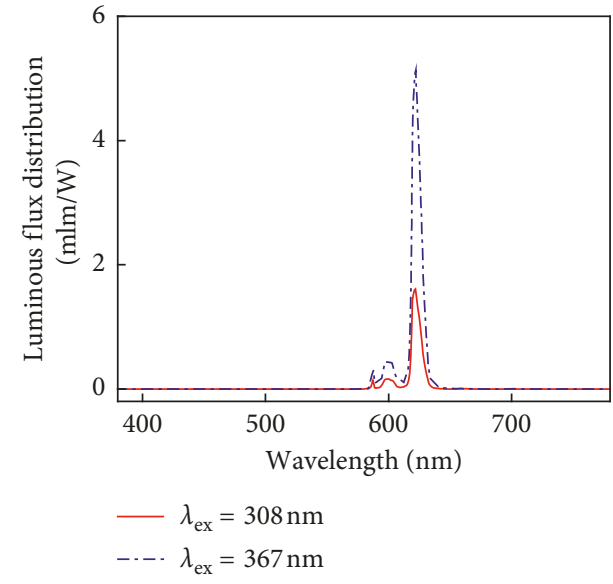

(b)

Figure 10: Luminous flux distributions of luminescence of Eu(BA)(TTA) $2 / \mathrm{PVP}$ (a) and Eu(BA)(TTA) 2 Phen/PVP (b) under 308 nm and $367 \mathrm{~nm}$ excitations.

TABle 2: Total luminous fluxes of Eu(BA)(TTA) $)_{2} / \mathrm{PVP}$ and Eu(BA)(TTA) ${ }_{2}$ Phen/PVP films under 308 and 367 nm UV-LEDs excitations.

\begin{tabular}{lcccc}
\hline \multirow{2}{*}{ Samples } & $\begin{array}{c}\text { Excitation wavelength } \\
(\mathrm{nm})\end{array}$ & $\begin{array}{c}\text { Excitation electric power } \\
(\mathrm{mW})\end{array}$ & $\begin{array}{c}\text { Luminous flux } \\
(\mathrm{mlm})\end{array}$ & $\begin{array}{c}\text { Luminous efficacy (lm/ } \\
\text { W) }\end{array}$ \\
\hline $\mathrm{Eu}(\mathrm{BA})(\mathrm{TTA})_{2} / \mathrm{PVP}$ & 308 & 115.61 & 13.20 & 0.114 \\
& 367 & 72.14 & 44.55 & 0.618 \\
\hline $\mathrm{Eu}(\mathrm{BA})(\mathrm{TTA})_{2}$ Phen/ & 308 & 115.61 & 16.60 & 0.144 \\
$\mathrm{PVP}$ & 367 & 72.14 & 52.34 & 0.726 \\
\hline
\end{tabular}

TABLE 3: Photon number ratio, reduced matrix, and J-O intensity parameters $\left(\Omega_{2}, \Omega_{4}\right.$, and $\left.\Omega_{6}\right)$ of Eu ${ }^{3+}$ in Eu(BA)(TTA) $2 / \mathrm{PVP}$ and $\mathrm{Eu}(\mathrm{BA})(\mathrm{TTA})_{2}$ Phen/PVP under $367 \mathrm{~nm}$ UVA-LED excitation.

\begin{tabular}{lccccccc}
\hline Samples & $\begin{array}{c}\text { Emission } \\
\text { transition }\end{array}$ & $\begin{array}{c}\text { Wavenumber } \\
\left(\mathrm{cm}^{-1}\right)\end{array}$ & $\left\|U^{(2)}\right\|^{2}$ & $\left\|U^{(4)}\right\|^{2}$ & $\left\|U^{(6)}\right\|^{2}$ & $\begin{array}{c}\text { Photon number } \\
\text { ratio }\end{array}$ & $\begin{array}{c}\text { J-O intensity parameter } \\
\left(10^{-20} \mathrm{~cm}^{2}\right)\end{array}$ \\
\hline \multirow{3}{*}{$\mathrm{Eu}(\mathrm{BA})(\mathrm{TTA})_{2} / \mathrm{PVP}$} & ${ }^{5} D_{0} \longrightarrow{ }^{7} F_{1}\left(N_{1}\right)$ & 16894 & 0 & 0 & 0 & - & - \\
& ${ }^{5} D_{0} \longrightarrow{ }^{7} F_{2}\left(N_{2}\right)$ & 16301 & 0.0032 & 0 & 0 & $N_{2} / N_{1}=15.777$ & $\Omega_{2}=30.221$ \\
& ${ }^{5} D_{0} \longrightarrow{ }^{7} F_{4}\left(N_{4}\right)$ & 14275 & 0 & 0.0023 & 0 & $N_{4} / N_{1}=1.720$ & $\Omega_{4}=6.880$ \\
\hline & ${ }^{5} D_{0} \longrightarrow{ }^{7} F_{6}\left(N_{6}\right)$ & 12416 & 0 & 0 & 0.0002 & $N_{6} / N_{1}=0.287$ & $\Omega_{6}=20.192$ \\
$\mathrm{Eu}(\mathrm{BA})(\mathrm{TTA})_{2}$ Phen $/{ }^{5} D_{0} \longrightarrow{ }^{7} F_{2}\left(N_{2}\right)$ & 16301 & 0.0032 & 0 & 0 & $N_{2} / N_{1}=15.439$ & $\Omega_{2}=29.579$ \\
$\mathrm{PVP}$ & ${ }^{5} D_{0} \longrightarrow{ }^{7} F_{4}\left(N_{4}\right)$ & 14275 & 0 & 0.0023 & 0 & $N_{4} / N_{1}=1.854$ & $\Omega_{4}=7.426$ \\
& ${ }^{5} D_{0} \longrightarrow{ }^{7} F_{6}\left(N_{6}\right)$ & 12336 & 0 & 0 & 0.0002 & $N_{6} / N_{1}=0.322$ & $\Omega_{6}=23.158$ \\
\hline
\end{tabular}

$\Omega_{2}$ values of $\mathrm{Eu}^{3+}$ in $\mathrm{Eu}(\mathrm{BA})(\mathrm{TTA})_{2} / \mathrm{PVP}$ and $\mathrm{Eu}(\mathrm{BA})(\mathrm{T}-$ TA $)_{2}$ Phen/PVP are derived to be $30.221 \times 10^{-20}$ and $29.579 \times 10^{-20} \mathrm{~cm}^{2}$, respectively. In particular, $\Omega_{2}$ is more sensitive to the asymmetry and the sequence of ligand fields, which strongly depends on the local environments of rareearth ions, such as high inversion asymmetrical and strong covalent environments. In addition, the $\Omega_{2}$ of $\mathrm{Eu}(\mathrm{BA})(\mathrm{T}$ $\mathrm{TA})_{2} \mathrm{Phen} / \mathrm{PVP}$ is smaller than that of $\mathrm{Eu}(\mathrm{BA})(\mathrm{TTA})_{2} / \mathrm{PVP}$, which confirms that the covalence degree of $\mathrm{Eu}^{3+}$ in the first coordination shell tiny decreases after the addition of Phen [58, 59].

The J-O intensity parameters $\Omega_{t}$, spontaneous transition probabilities $A_{\mathrm{ij}}$, branching ratios $\beta_{\mathrm{ij}}$, and calculated radiative lifetimes $\tau_{\text {rad }}$ are calculated and listed in Table 4 . The $A_{\mathrm{ij}}$ of ${ }^{5} D_{0} \longrightarrow{ }^{7} F_{2}$ transition are up to $954.7 \mathrm{~s}^{-1}$ and $942.6 \mathrm{~s}^{-1}$ in
$\mathrm{Eu}(\mathrm{BA})(\mathrm{TTA})_{2} / \mathrm{PVP}$ and $\mathrm{Eu}(\mathrm{BA})(\mathrm{TTA})_{2} \mathrm{Phen} / \mathrm{PVP}$, respectively, and the $\beta_{\mathrm{ij}}$ are also found as high as $83.99 \%$ and $82.94 \%$, respectively, which are stronger than other transitions indicating that the ${ }^{5} D_{0} \longrightarrow{ }^{7} F_{2}$ transition is efficient and dominant in europium complexes doped PVP thin films. These results further confirm the suitability of multiligand europium complexes/PVP as UV-visible conversion layers for enhanced solar cells.

Stimulated emission cross section $\sigma_{\mathrm{em}}$ is one of the most basic physical quantities to evaluate the energy extraction efficiency from rare-earth doped optical materials, not only for a fundamental understanding of the excitation and depopulation process but also for the optimization of laser materials, which is determined through the FuchtbauerLadenburg equation [60]: 
TABLE 4: Spontaneous transition probabilities $\mathrm{A}_{\mathrm{ij}}$, branching ratios $\beta_{\mathrm{ij}}$, and calculated radiative lifetimes $\tau_{\mathrm{rad}}$ of ${ }^{5} D_{0}$ in Eu(BA)(TTA) $2 / \mathrm{PVP}$ and $\mathrm{Eu}(\mathrm{BA})(\mathrm{TTA})_{2}$ Phen/PVP.

\begin{tabular}{|c|c|c|c|c|c|}
\hline Samples & Transition & Energy $\left(\mathrm{cm}^{-1}\right)$ & $A_{\mathrm{ij}}\left(\mathrm{s}^{-1}\right)$ & $\beta_{\mathrm{ij}}(\%)$ & $\tau_{\mathrm{rad}}(\mu \mathrm{s})$ \\
\hline \multirow{4}{*}{$\mathrm{Eu}(\mathrm{BA})(\mathrm{TTA})_{2} / \mathrm{PVP}$} & ${ }^{5} D_{0} \longrightarrow{ }^{7} F_{1}$ & 16894 & 60.51 & 5.32 & \multirow{4}{*}{879.7} \\
\hline & ${ }^{5} \mathrm{D}_{0} \longrightarrow{ }^{7} \mathrm{~F}_{2}$ & 16301 & 954.71 & 83.99 & \\
\hline & ${ }^{5} D_{0} \longrightarrow{ }^{7} F_{4}$ & 14275 & 104.10 & 9.16 & \\
\hline & ${ }^{5} D_{0} \longrightarrow{ }^{7} F_{6}$ & 12416 & 17.37 & 1.53 & \\
\hline \multirow{4}{*}{$\mathrm{Eu}(\mathrm{BA})(\mathrm{TTA})_{2} \mathrm{Phen} / \mathrm{PVP}$} & ${ }^{5} D_{0} \longrightarrow{ }^{7} F_{1}$ & 16916 & 61.05 & 5.37 & \multirow{4}{*}{879.9} \\
\hline & ${ }^{5} \mathrm{D}_{0} \longrightarrow{ }^{7} \mathrm{~F}_{2}$ & 16301 & 942.55 & 82.94 & \\
\hline & ${ }^{5} \mathrm{D}_{0} \longrightarrow{ }^{7} \mathrm{~F}_{4}$ & 14275 & 113.22 & 9.96 & \\
\hline & ${ }^{5} \mathrm{D}_{0} \longrightarrow{ }^{7} \mathrm{~F}_{6}$ & 12336 & 19.67 & 1.73 & \\
\hline
\end{tabular}

$$
\sigma_{\mathrm{em}}=\frac{A_{\mathrm{rad}}}{8 \pi c n^{2}} \times \frac{\lambda^{5} N(\lambda)}{\int \lambda N(\lambda) d \lambda},
$$

where $n, A_{\text {rad }}$, and $N(\lambda)$ represent the refractive index, spontaneous transition probability, and emission photon distribution, respectively. As is clearly seen in Figure 11, there are four visible emission bands, whose peaks are located at 592,615, 701, and $810 \mathrm{~nm}$ corresponding to the ${ }^{5} D_{0} \longrightarrow{ }^{7} F_{J}(J=1,2,4,6)$ transitions of $\mathrm{Eu}^{3+}$, respectively. The maximum values $\sigma_{\text {em-max }}$ for ${ }^{5} D_{0} \longrightarrow{ }^{7} F_{2}$ transitions of $\mathrm{Eu}^{3+}$ in $\mathrm{Eu}(\mathrm{BA})(\mathrm{TTA})_{2} / \mathrm{PVP}$ and $\mathrm{Eu}(\mathrm{BA})(\mathrm{TTA})_{2}$ Phen/PVP peaking at $615 \mathrm{~nm}$ both are derived to be $7.90 \times 10^{-21} \mathrm{~cm}^{2}$, indicating both of them have approximate emission capability. As for the increment of fluorescence intensity, which can be interpreted that the addition of Phen leads to the combination of the heterogeneous ligand field and the antiparity of the $4 \mathrm{f}$ configuration levels, resulting in the intense absorption property and the prominent radiation behavior [61]. The large emission cross section enables the europium complexes/PVP to be a promising material for photon conversion materials.

3.4. Optical Absorbability and Thermal Stability. The transmission spectra and the images of $\mathrm{Eu}(\mathrm{BA})(\mathrm{TTA})_{2} / \mathrm{PVP}$ and $\mathrm{Eu}(\mathrm{BA})(\mathrm{TTA})_{2}$ Phen/PVP are depicted in Figure 12(a), respectively. Both of them show up to $95 \%$ transparency at $350-800 \mathrm{~nm}$ and the broad band at $200-350 \mathrm{~nm}$ exhibits an intense absorbability of ligands, indicating the PVP is a suitable matrix for doping rare-earth complexes into photon conversion materials. The optical absorption exhibits excellent absorption properties for multiligand europium complexes/PVP upon UV radiation, as depicted in Figure $12(\mathrm{~b})$. As for the $\mathrm{Eu}(\mathrm{BA})(\mathrm{TTA})_{2} / \mathrm{PVP}$, the absorption of BA at 234 and $273 \mathrm{~nm}$ is primarily attributed to the $n \longrightarrow \sigma^{*}$ transitions of $E$ absorption band and $\pi \longrightarrow \pi^{*}$ transitions of $\mathrm{B}$ absorption band $[62,63]$, respectively, and the strong absorption of TTA at $350 \mathrm{~nm}$ is assigned to the $n \longrightarrow \pi^{*}$ electron transition. With the addition of Phen, the energy transfer is more effective; meanwhile, the effect of Phen is reconfirmed; that is, Phen has no contribution in increasing the emission section while enhances the absorption of the UV. The absorption coefficient curve is nearly unchangeable after $400 \mathrm{~nm}$, which implies that the ligands can effectively transfer the excited state energy to the

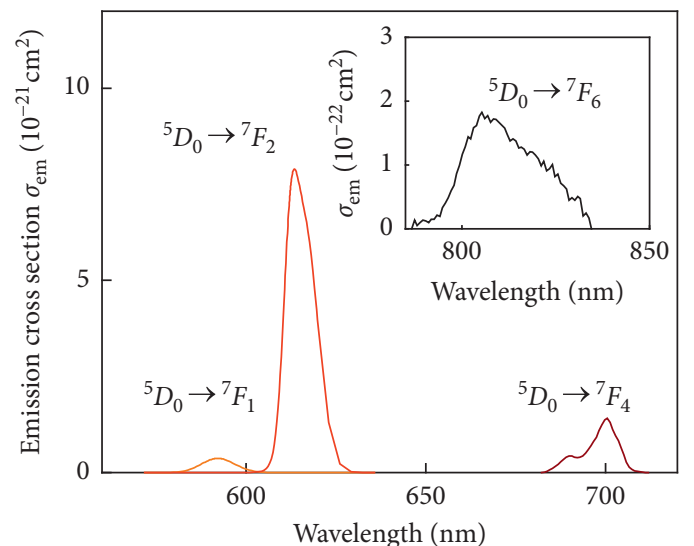

(a)

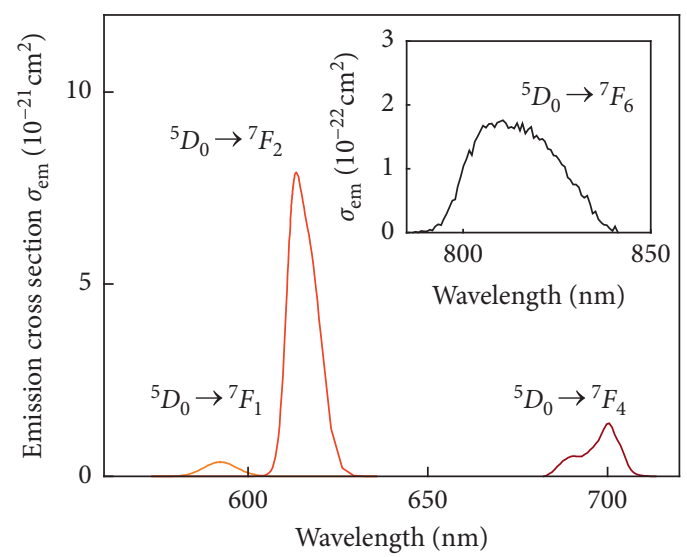

(b)

Figure 11: Emission cross-sectional profiles of $\mathrm{Eu}^{3+}$ in $\mathrm{Eu}(\mathrm{BA})(\mathrm{TTA})_{2} / \mathrm{PVP}$ (a) and $\mathrm{Eu}(\mathrm{BA})(\mathrm{TTA})_{2}$ Phen/PVP (b) under $367 \mathrm{~nm}$ UVA-LED excitation. Insets: emission cross-sectional profiles of ${ }^{5} D_{0} \longrightarrow{ }^{7} F_{6}$ transition of $\mathrm{Eu}^{3+}$ in $\mathrm{Eu}(\mathrm{BA})(\mathrm{TTA})_{2} / \mathrm{PVP}$ and $\mathrm{Eu}(\mathrm{BA})(\mathrm{TTA})_{2}$ Phen/PVP, respectively.

emission state of $\mathrm{Eu}^{3+}$ through the nonradiated transition, thus sensitizing luminescence and making up for the small absorption coefficient of $\mathrm{Eu}^{3+}$ in the UV region [64]. And the multiligand europium complexes are put into a dark room with a hole for guiding sunlight through a glass tube and attached with foil in the inner wall to avoid energy losses. Meanwhile, the bright red fluorescence of $\mathrm{Eu}(\mathrm{BA})(\mathrm{TTA})_{2} /$ $\mathrm{PVP}$ and $\mathrm{Eu}(\mathrm{BA})(\mathrm{TTA})_{2} \mathrm{Phen} / \mathrm{PVP}$ exhibits an effective response to the sunlight, as shown in Figure 12(b). 


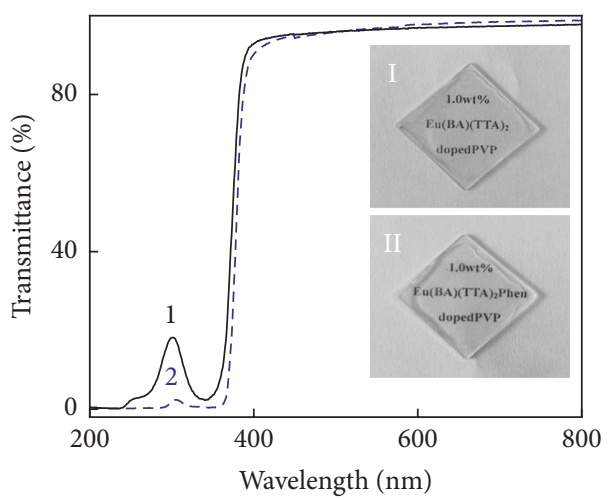

(a)

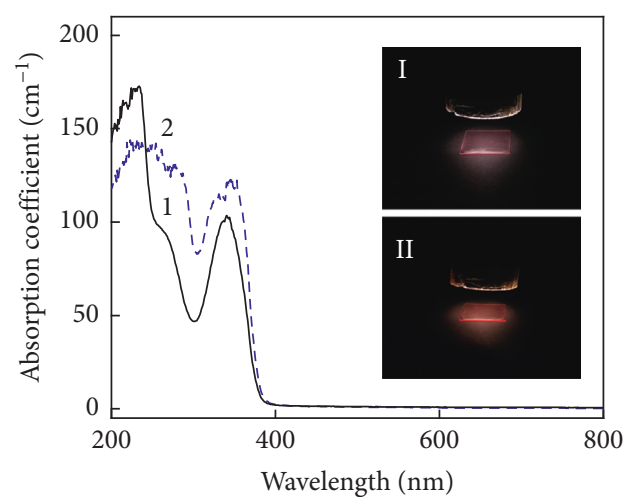

(b)

FIgURE 12: UV-Vis transmission spectra (a) and absorption spectra (b) of Eu(BA)(TTA) 2 /PVP (curve 1) and Eu(BA)(TTA) 2 Phen/PVP (curve 2). The thickness of $\mathrm{Eu}(\mathrm{BA})(\mathrm{TTA})_{2} / \mathrm{PVP}$ and $\mathrm{Eu}(\mathrm{BA})(\mathrm{TTA})_{2} \mathrm{Phen} / \mathrm{PVP}$ is $0.160 \mathrm{~mm}$ and $0.198 \mathrm{~mm}$, respectively. The insets are the samples without (I) and with (II) Phen under direct sunlight, respectively.

Thermodynamic property is essential to europium complexes/PVP for practical applications as optical materials; therefore, the DSC-TGA analyses of $\mathrm{Eu}(\mathrm{BA})(\mathrm{TTA})_{2}$ / $\mathrm{PVP}$ and $\mathrm{Eu}(\mathrm{BA})(\mathrm{TTA})_{2} \mathrm{Phen} / \mathrm{PVP}$ have been carried out to explore their degradation behavior, as illustrated in Figure 13. The TGA curves of $\mathrm{Eu}(\mathrm{BA})(\mathrm{TTA})_{2} / \mathrm{PVP}$ and $\mathrm{Eu}(\mathrm{BA})(\mathrm{TTA})_{2} \mathrm{Phen} / \mathrm{PVP}$ are similar, and both of them show $5 \%$ weightlessness at $100^{\circ} \mathrm{C}$, which is ascribed to the water detach from the samples with an obvious endothermic peak. Furthermore, in the $200-400^{\circ} \mathrm{C}$ temperature ranges, an exothermic peak appears due to the sample melting. Besides, the curve reveals that the major weightlessness events occur at the temperature interval $\left(400-500^{\circ} \mathrm{C}\right)$, implying the thermal decomposition behavior of PVP appears with the emergence of endothermic peaks as well. The DSC curve tends to a constant at $470-600^{\circ} \mathrm{C}$, indicating the decomposition of the coordination compound is complete. The results further confirm that the composition of the $\mathrm{Eu}(\mathrm{BA})(\mathrm{TTA})_{2}$ and $\mathrm{Eu}(\mathrm{BA})(\mathrm{TTA})_{2}$ Phen doped PVP has excellent thermal stability for the research and development of electronic devices.

\section{Conclusions}

The films of $\mathrm{Eu}(\mathrm{BA})(\mathrm{TTA})_{2}$ and $\mathrm{Eu}(\mathrm{BA})(\mathrm{TTA})_{2}$ Phen doped polyvinylpyrrolidone (PVP) have been synthesized, and the bright red fluorescence is observed under ultraviolet radiation. Absorption and emission spectra confirm that the composite material with good thermodynamic stability can convert ultraviolet radiation into visible light efficiently and suggest the interaction between PVP and $\mathrm{Eu}^{3+}$. Under $367 \mathrm{~nm}$ UVA-LED pump source, the highest emission powers, emission photon numbers, and luminous efficacy are derived to be 204.8 and $243.2 \mu \mathrm{W}, 635.9 \times 10^{12}$ and $754.9 \times 10^{12} \mathrm{cps}$, and $61.8 \%$ and $72.6 \% \mathrm{~lm} / \mathrm{W}$ for $\mathrm{Eu}(\mathrm{BA})(\mathrm{TTA})_{2} / \mathrm{PVP}$ and $\mathrm{Eu}(\mathrm{BA})(\mathrm{TTA})_{2}$ Phen/PVP thin films, which verifies the effective utilization of UVA radiation by introducing multiligands. Simultaneously, the quantum yields are up to $57.87 \%$ and $62.03 \%$ for without and with Phen, respectively. Meanwhile, the J-O intensity

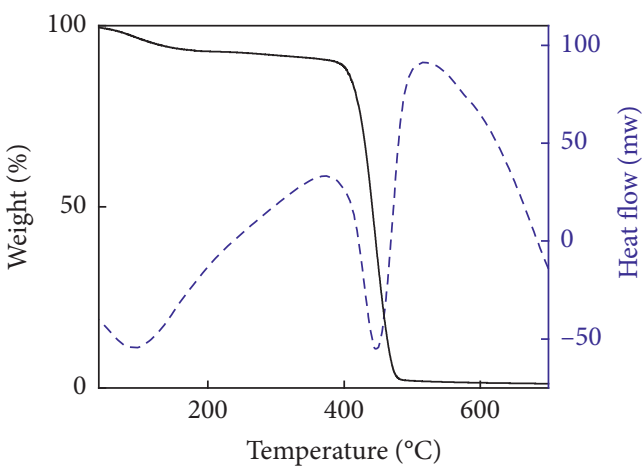

(a)

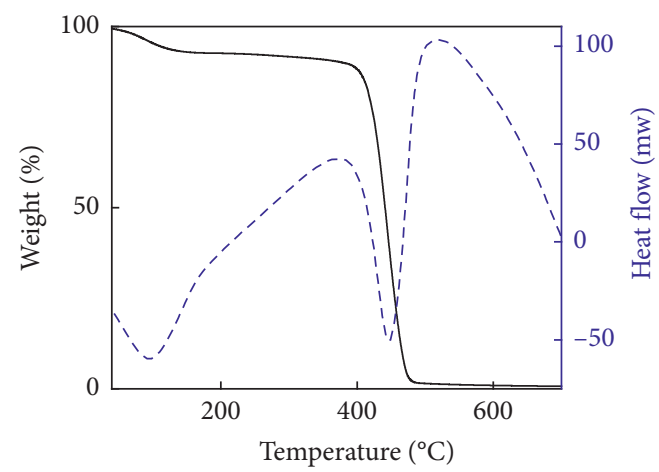

(b)

Figure 13: DSC-TAG analyses of $\mathrm{Eu}(\mathrm{BA})(\mathrm{TTA})_{2} / \mathrm{PVP}$ (a) and $\mathrm{Eu}(\mathrm{BA})(\mathrm{TTA})_{2}$ Phen/PVP (b).

parameter $\Omega_{2}$ of $\mathrm{Eu}(\mathrm{BA})(\mathrm{TTA})_{2} / \mathrm{PVP}$ is higher than $\mathrm{Eu}(\mathrm{BA})(\mathrm{TTA})_{2}$ Phen/PVP, confirming that the local asymmetry around $\mathrm{Eu}^{3+}$ increases after the addition of Phen. Efficient photon emission demonstrates the availability of multiligand europium complexes as an attractive UV radiation conversion material for enhanced solar cells.

\section{Data Availability}

The data used to support the findings of this study are available from the corresponding author upon request. 


\section{Conflicts of Interest}

The authors declare that there are no conflicts of interest regarding the publication of this paper.

\section{Acknowledgments}

The research work was funded by the Support Program for Innovative Talents of Universities from Education Department of Liaoning Province, China (Grant no. LR2016014), the Scientific and Technological Research Project from Education Department of Liaoning Province, China (Grant no. 2017J050), and the Scientific and Technological Innovation Team Program of Liaoning Province, China (LT2017017).

\section{References}

[1] H. Tsai, R. Asadpour, J.-C. Blancon et al., "Light-induced lattice expansion leads to high-efficiency perovskite solar cells," Science, vol. 360, no. 6384, pp. 67-70, 2018.

[2] Z. Wen, M. H. Yeh, H. Guo et al., "Self-powered textile for wearable electronics by hybridizing fiber-shaped nanogenerators, solar cells, and supercapacitors," Science Advances, vol. 2, no. 10, article e1600097, 2016.

[3] V. Jovanov, E. Moulin, F.-J. Haug et al., "From randomly selftextured substrates to highly efficient thin film solar cells: influence of geometric interface engineering on light trapping, plasmonic losses and charge extraction," Solar Energy Materials and Solar Cells, vol. 160, pp. 141-148, 2017.

[4] M. Grätzel, "Photoelectrochemical cells," Nature, vol. 414, no. 6861, pp. 338-344, 2001.

[5] A. Gavriluta, T. Fix, A. Nonat, A. Slaoui, J.-F. Guillemoles, and L. J. Charbonnière, "Tuning the chemical properties of europium complexes as downshifting agents for copper indium gallium selenide solar cells," Journal of Materials Chemistry A, vol. 5, no. 27, pp. 14031-14040, 2017.

[6] L. Jiang, J. Zheng, W. Chen et al., "High-performance perovskite solar cells with a weak covalent $\mathrm{TiO}_{2}: \mathrm{Eu}^{3+}$ mesoporous structure," ACS Applied Energy Materials, vol. 1, no. 1, pp. 93-102, 2017.

[7] H. Fouad, S. G. Ansari, A. A. Khan, and Z. A. Ansari, "Europium doped $\mathrm{TiO}_{2}$ : an efficient photoanode material for dye sensitized solar cell," Journal of Materials Science: Materials in Electronics, vol. 28, no. 9, pp. 6873-6879, 2017.

[8] J. Jiao, S. Gai, Y. Li et al., " $\mathrm{NaYbF}_{4}: \mathrm{Tb} / \mathrm{Eu}$ modified with organic antenna for improving performance of polymer solar cells," Electrochimica Acta, vol. 260, pp. 959-964, 2018.

[9] Y. Iso, S. Takeshita, and T. Isobe, "Effects of $\mathrm{YVO}_{4}: \mathrm{Bi}^{3+}$, $\mathrm{Eu}^{3+}$ Nanophosphors spectral down-shifter on properties of monocrystalline silicon photovoltaic module," Journal of The Electrochemical Society, vol. 159, no. 3, pp. J72-J76, 2012.

[10] S. J. McCormack, H. Ahmed, and J. Doran, "Increased shortcircuit current density and external quantum efficiency of silicon and dye sensitised solar cells through plasmonic luminescent down-shifting layers," Solar Energy, vol. 126, pp. 146-155, 2016.

[11] B. Rajamouli, R. Devi, A. Mohanty, V. Krishnan, and S. Vaidyanathan, "Effects of electron-withdrawing groups in imidazole-phenanthroline ligands and their influence on the photophysical properties of EuIII complexes for white lightemitting diodes," New Journal of Chemistry, vol. 41, no. 18, pp. 9826-9839, 2017.
[12] T. Monzón-Hierro, J. Sanchiz, S. González-Pérez et al., “A new cost-effective polymeric film containing an $\mathrm{Eu}(\mathrm{III})$ complex acting as UV protector and down-converter for Sibased solar cells and modules," Solar Energy Materials and Solar Cells, vol. 136, pp. 187-192, 2015.

[13] M. A. van de Haar, J. Werner, N. Kratz et al., "Increasing the effective absorption of $\mathrm{Eu}^{3+}$-doped luminescent materials towards practical light emitting diodes for illumination applications," Applied Physics Letters, vol. 112, no. 13, article 132101, 2018.

[14] J. Yue, Y. Xiao, Y. Li, G. Han, Y. Zhang, and W. Hou, "Enhanced photovoltaic performances of the dye-sensitized solar cell by utilizing rare-earth modified tin oxide compact layer," Organic Electronics, vol. 43, pp. 121-129, 2017.

[15] D. Zhou, D. Liu, G. Pan et al., "Cerium and ytterbium codoped halide perovskite quantum dots: a novel and efficient downconverter for improving the performance of silicon solar cells," Advanced Materials, vol. 29, no. 42, article 1704149, 2017.

[16] K. A. Romanova, A. Y. Freidzon, A. A. Bagaturyants, and Y. G. Galyametdinov, "Ab initio study of energy transfer pathways in dinuclear lanthanide complex of europium(III) and terbium(III) ions," Journal of Physical Chemistry A, vol. 118, no. 47, pp. 11244-11252, 2014.

[17] A. V. Shurygin, V. V. Korochentsev, A. I. Cherednichenko, A. G. Mirochnik, I. V. Kalinovskaya, and V. I. Vovna, "Electronic structure and optical properties of $\mathrm{Eu}(\mathrm{III})$ tris$\beta$-diketonate adducts with 1,10-phenanthroline," Journal of Molecular Structure, vol. 1155, pp. 133-142, 2018.

[18] M. Bilmez, A. Degirmenci, M. P. Algi, and F. Algi, "A phosphorescent fluoride probe based on Eu(111)-DO3A clicked with a 2,5-di(thien-2-yl)pyrrole scaffold," New Journal of Chemistry, vol. 42, no. 1, pp. 450-457, 2018.

[19] Y. M. Fadieiev, S. S. Smola, M. Y. Rusakova, E. V. Malinka, and N. V. Rusakova, "Spectral-luminescent properties of aerosils with adsorbed adducts of Eu(III) tris- $\beta$-diketonates and 1,10-phenanthroline," Journal of Luminescence, vol. 194, pp. 631-635, 2018.

[20] R. Borja-Urby, L. A. Diaz-Torres, P. Salas, C. Angeles-Chavez, and O. Meza, "Strong broad green UV-excited photoluminescence in rare earth $(\mathrm{RE}=\mathrm{Ce}, \mathrm{Eu}, \mathrm{Dy}, \mathrm{Er}, \mathrm{Yb})$ doped barium zirconate," Materials Science and Engineering: B, vol. 176, no. 17, pp. 1388-1392, 2011.

[21] P. Lu, J.-L. Zhang, Y.-L. Liu et al., "Synthesis and characteristic of the $\mathrm{Fe}_{3} \mathrm{O}_{4} @ \mathrm{SiO}_{2} @ \mathrm{Eu}(\mathrm{DBM})_{3} \cdot 2 \mathrm{H}_{2} \mathrm{O} / \mathrm{SiO}_{2}$ luminomagnetic microspheres with core-shell structure," Talanta, vol. 82, no. 2, pp. 450-457, 2010.

[22] A. V. Kharcheva, N. E. Borisova, A. V. Ivanov et al., "Effect of aliphatic chain length in the ligand on photophysical properties and thin films morphology of the europium complexes," Russian Journal of Inorganic Chemistry, vol. 63, no. 2, pp. 219-228, 2018.

[23] P. Wang, Y. Wang, and L. Tong, "Functionalized polymer nanofibers: a versatile platform for manipulating light at the nanoscale," Light: Science \& Applications, vol. 2, no. 10, p. e102, 2013.

[24] N. T. Kalyani, S. J. Dhoble, and R. B. Pode, "Enhancement of photoluminescence in various $\mathrm{Eu}_{\mathrm{x}} \mathrm{Re}_{(1-\mathrm{x})} \mathrm{TTA}_{3}$ Phen $(\mathrm{Re}=\mathrm{Y}$, $\mathrm{Tb})$ complexes molecularly doped in PMMA," Indian Journal of Physics, vol. 86, no. 7, pp. 613-618, 2012.

[25] K. Singh, R. Boddula, and S. Vaidyanathan, "Versatile luminescent europium(III)- $\beta$-diketonate-imidazo-bipyridyl complexes intended for white LEDs: a detailed photophysical and theoretical study," Inorganic Chemistry, vol. 56, no. 15, pp. 9376-9390, 2017. 
[26] J. Yang, L. Zhang, L. Wen, S. Dai, L. Hu, and Z. Jiang, "Comparative investigation on energy transfer mechanisms between $\mathrm{Er}^{3+}$ and $\mathrm{Ce}^{3+}\left(\mathrm{Eu}^{3+}, \mathrm{Tb}^{3+}\right)$ in tellurite glasses," Chemical Physics Letters, vol. 384, no. 4-6, pp. 295-298, 2004.

[27] Y. Shi, C. Dong, and J. Shi, "Study on morphology evolution and luminescence properties of truncated octahedron-like BiOCl: $\mathrm{xEu}^{3+}$ phosphors," Materials Science and Engineering: B, vol. 228, pp. 28-37, 2018.

[28] S. Ishaq, A. Sikora, N. Scheidler, C. Hambleton, and J. E. Katz, "Enhancement of water oxidation photocurrent for hematite thin films electrodeposited with polyvinylpyrrolidone," Journal of The Electrochemical Society, vol. 163, no. 13, pp. F1330-F1336, 2016.

[29] S. Fan, S. Wang, H. Sun, S. Sun, G. Gao, and L. Hu, "Efficient dual-modeup-conversion and down-shifting emission in $\beta-\mathrm{NaYF}_{4}: \mathrm{Yb}^{3+}, \mathrm{Er}^{3+}$ microcrystals via ion exchange," Journal of the American Ceramic Society, vol. 100, no. 7, pp. 30613069, 2017.

[30] K. M. Koczkur, S. Mourdikoudis, L. Polavarapu, and S. E. Skrabalak, "Polyvinylpyrrolidone (PVP) in nanoparticle synthesis," Dalton Transactions, vol. 44, no. 41, pp. 1788317905, 2015.

[31] C. Ming, F. Song, X. Ren et al., "Converting sunlight into red light in fluorosilicate glass for amorphous silicon solar cells," Journal of Luminescence, vol. 183, pp. 433-436, 2017.

[32] M. P. Dandekar, S. G. Itankar, S. B. Kondawar, D. V. Nandanwar, and P. Koinkar, "Photoluminescent electrospun europium complex Eu(TTA) ${ }_{3}$ phen embedded polymer blends nanofibers," Optical Materials, vol. 85, pp. 483-490, 2018.

[33] D. Wang, W. Cao, and J. Fan, "Synthesis and luminescence properties of the europium quaternary complexes nanoparticles," Science China Chemistry, vol. 57, no. 6, pp. 791-796, 2014.

[34] T. A. Kovacs, M. C. F. C. Felinto, T. B. Paolini et al., "Synthesis and photoluminescence properties of $\left[\mathrm{Eu}(\mathrm{dbm})_{3} \cdot \mathrm{PX}\right]$ and $\left[\mathrm{Eu}(\mathrm{acac})_{3} \cdot \mathrm{PX}\right]$ complexes," Journal of Luminescence, vol. 193, pp. 98-105, 2018.

[35] P. Du and J. S. Yu, " $\mathrm{Eu}^{3+}$-activated $\mathrm{La}_{2} \mathrm{MoO}_{6}-\mathrm{La}_{2} \mathrm{WO}_{6}$ redemitting phosphors with ultrabroad excitation band for white light-emitting diodes," Scientific Reports, vol. 7, no. 1, article 11953, 2017.

[36] R. C. Holz and L. C. Thompson, "Spectroscopic and structural characterization of the nine-coordinate adduct of tris(dipivaloylmethanato)europium(III) with $2,2^{\prime}: 6^{\prime}, 2^{\prime \prime}$-terpyridine," Inorganic Chemistry, vol. 27, no. 25, pp. 4640-4644, 1988.

[37] S. T. Frey and W. D. W. Horrocks Jr., "On correlating the frequency of the ${ }^{7} F_{0} \longrightarrow{ }^{5} D_{0}$ transition in $\mathrm{Eu}^{3+}$ complexes with the sum of 'nephelauxetic parameters' for all of the coordinating atoms," Inorganica Chimica Acta, vol. 229, no. 1-2, pp. 383-390, 1995.

[38] M. Bortoluzzi, G. Paolucci, M. Gatto et al., "Preparation of photoluminescent PMMA doped with tris(pyrazol-1-yl) borate lanthanide complexes," Journal of Luminescence, vol. 132, no. 9, pp. 2378-2384, 2012.

[39] H. Rahimian, Y. Hatefi, A. Dehghan Hamedan, S. P. Shirmardi, and H. Mokhtari, "Structural and optical investigations on $\mathrm{Eu}^{3+}$ doped fluorophosphate glass and nano glass-ceramics," Journal of Non-Crystalline Solids, vol. 487, pp. 46-52, 2018.

[40] J. Wang, H. Lin, Q. Huang et al., "Structure and luminescence behavior of a single-ion activated single-phased
$\mathrm{Ba}_{2} \mathrm{Y}_{3}\left(\mathrm{SiO}_{4}\right)_{3} \mathrm{~F}: \mathrm{Eu}$ white-light phosphor," Journal of Materials Chemistry C, vol. 5, no. 7, pp. 1789-1797, 2017.

[41] H. Yu, Y. Li, Y. Song et al., "Ultralong well-aligned $\mathrm{TiO}_{2}$ : $\mathrm{Ln}^{3+}(\mathrm{Ln}=\mathrm{Eu}, \mathrm{Sm}$, or Er) fibres prepared by modified electrospinning and their temperature-dependent luminescence," Scientific Reports, vol. 7, no. 1, article 44099, 2017.

[42] R. Boddula, K. Singh, S. Giri, and S. Vaidyanathan, "Controlled energy transfer from a ligand to an $\mathrm{Eu}^{\mathrm{III}}$ ion: a unique strategy to obtain bright-white-light emission and its versatile applications," Inorganic Chemistry, vol. 56, no. 17, pp. 10127-10130, 2017.

[43] T. Li, P. Li, Z. Wang, S. Xu, Q. Bai, and Z. Yang, "Coexistence phenomenon of $\mathrm{Ce}^{3+}-\mathrm{Ce}^{4+}$ and $\mathrm{Eu}^{2+}-\mathrm{Eu}^{3+}$ in Ce/Eu co-doped $\mathrm{LiBaB}_{9} \mathrm{O}_{15}$ phosphor: luminescence and energy transfer," Physical Chemistry Chemical Physics, vol. 19, no. 5, pp. 4131-4138, 2017.

[44] C. Yang, L. Zhang, Z. Wang, T. Li, F. Li, and W. Cao, "Nanostructured $\mathrm{NaLa}\left(\mathrm{MoO}_{4}\right)_{2}$ and $\mathrm{Eu}^{3+}$-doped $\mathrm{NaLa}\left(\mathrm{MoO}_{4}\right)_{2}$ : synthesis, characterizations, photoluminescence and superhydrophobic properties," Materials Science and Engineering: B, vol. 207, pp. 39-46, 2016.

[45] L. Jiang, J.-W. Zheng, W.-C. Chen et al., "Tuning coordination environment: better photophysical performance of europium(III) complex," Journal of Physical Chemistry C, vol. 121, no. 11, pp. 5925-5930, 2017.

[46] P. K. Shahi, A. K. Singh, S. K. Singh, S. B. Rai, and B. Ullrich, "Revelation of the technological versatility of the $\mathrm{Eu}$ (TTA) ${ }_{3}$ Phen complex by demonstrating energy harvesting, ultraviolet light detection, temperature sensing, and laser applications," ACS Applied Materials \& Interfaces, vol. 7, no. 33, pp. 18231-18239, 2015.

[47] A. Huang, Z. Yang, C. Yu, Z. Chai, J. Qiu, and Z. Song, "Tunable and white light emission of a single-phased $\mathrm{Ba}_{2} \mathrm{Y}\left(\mathrm{BO}_{3}\right)_{2} \mathrm{Cl}: \mathrm{Bi}^{3+}, \mathrm{Eu}^{3+}$ phosphor by energy transfer for ultraviolet converted white LEDs," Journal of Physical Chemistry C, vol. 121, no. 9, pp. 5267-5276, 2017.

[48] G. Wang, W. Qin, J. Zhang et al., "Synthesis and spectral properties of $\mathrm{Eu}^{3+}$-doped $\mathrm{YF}_{3}$ nanobundles," Journal of Fluorine Chemistry, vol. 129, no. 7, pp. 621-624, 2008.

[49] Y. Hasegawa, A. Ishii, Y. Inazuka et al., "The enhanced intramolecular energy transfer and strengthened ff luminescence of a stable helical Eu complex in ionic liquids," Molecules, vol. 23, no. 2, p. 55, 2018.

[50] H. Li, L. Shen, E. Y. B. Pun, Y. Song, and H. Lin, "Differentiation of photon generation in single- and bi- ligand europium complexes doped poly methyl methacrylate," Journal of Non-Crystalline Solids, vol. 448, pp. 89-95, 2016.

[51] S. Li and X. Zhao, "Oxygen sensing nanofibers doped with red-emitting $\mathrm{Eu}(\mathrm{III})$ complex: synthesis, characterization, mechanism, and sensing performance," Synthetic Metals, vol. 161, no. 9-10, pp. 737-742, 2011.

[52] J. L. Zhang, B. W. Chen, X. Luo, and K. Du, "Eu(III) complexdoped PMMA having fast radiation rate and high emission quantum efficiency," Chinese Chemical Letters, vol. 23, no. 8, pp. 945-948, 2012.

[53] C. Zhou, H. Lin, Y. Tian et al., "Luminescent zerodimensional organic metal halide hybrids with near-unity quantum efficiency," Chemical Science, vol. 9, no. 3, pp. 586-593, 2018.

[54] Y. Li, Y. Wang, E. Y. B. Pun, and H. Lin, "Bead-on-string fibers electrospun from terbium acetylacetonate hydrate doped poly methyl methacrylate," Optical Materials Express, vol. 8, no. 2, pp. 276-288, 2018. 
[55] T. Grzyb, A. Szczeszak, A. Shyichuk et al., "Comparative studies of structure, spectroscopic properties and intensity parameters of tetragonal rare earth vanadate nanophosphors doped with Eu(III)," Journal of Alloys and Compounds, vol. 741, pp. 459-472, 2018.

[56] S. G. P. Kumar, R. H. Krishna, N. Kottam et al., "Understanding the photoluminescence behaviour in nano $\mathrm{CaZrO}_{3}: \mathrm{Eu}^{3+}$ pigments by Judd-Ofelt intensity parameters," Dyes and Pigments, vol. 150, pp. 306-314, 2018.

[57] M. Dejneka, E. Snitzer, and R. E. Riman, "Blue, green and red fluorescence and energy transfer of $\mathrm{Eu}^{3+}$ in fluoride glasses," Journal of Luminescence, vol. 65, no. 5, pp. 227-245, 1995.

[58] P. Du, X. Huang, and J. S. Yu, "Facile synthesis of bifunctional $\mathrm{Eu}^{3+}$-activated $\mathrm{NaBiF}_{4}$ red-emitting nanoparticles for simultaneous white light-emitting diodes and field emission displays," Chemical Engineering Journal, vol. 337, pp. 91-100, 2018.

[59] P. Jena, S. K. Gupta, N. K. Verma, A. K. Singh, and R. M. Kadam, "Energy transfer dynamics and time resolved photoluminescence in $\mathrm{BaWO}_{4}: \mathrm{Eu}^{3+}$ nanophosphors synthesized by mechanical activation," New Journal of Chemistry, vol. 41, no. 17, pp. 8947-8958, 2017.

[60] Q. Liu, Y. Tian, C. Wang et al., "Different dominant transitions in holmium and ytterbium codoped oxyfluoride glass and glass ceramics originating from varying phonon energy environments," Physical Chemistry Chemical Physics, vol. 19, no. 44, pp. 29833-29839, 2017.

[61] Y. Hasegawa, M. Yamamuro, Y. Wada, N. Kanehisa, Y. Kai, and S. Yanagida, "Luminescent polymer containing the $\mathrm{Eu}(\mathrm{III})$ complex having fast radiation rate and high emission quantum efficiency," Journal of Physical Chemistry A, vol. 107, no. 11, pp. 1697-1702, 2003.

[62] B. Gao, L. Chen, and T. Chen, "Effect of electron-donating substituent groups on aromatic ring on photoluminescence properties of complexes of benzoic acid-functionalized polysulfone with $\mathrm{Eu}(\mathrm{III})$ ions," Physical Chemistry Chemical Physics, vol. 17, no. 38, pp. 25322-25332, 2015.

[63] J. Tanaka, S. Nagakura, and M. Kobayashi, "Ultraviolet and infrared absorption spectra of substituted acetophenones and benzoic acids," Journal of Chemical Physics, vol. 24, no. 2, pp. 311-315, 1956.

[64] X. Wang, L. Huang, S. Zhao, and S. Xu, "Eu ${ }^{3+}$ doped heavy germanate scintillating glasses," Journal of Luminescence, vol. 196, pp. 256-258, 2018. 


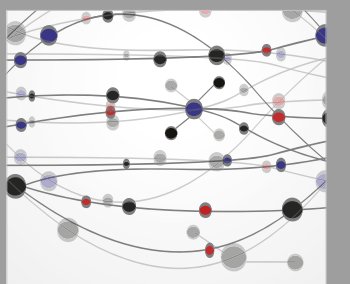

The Scientific World Journal
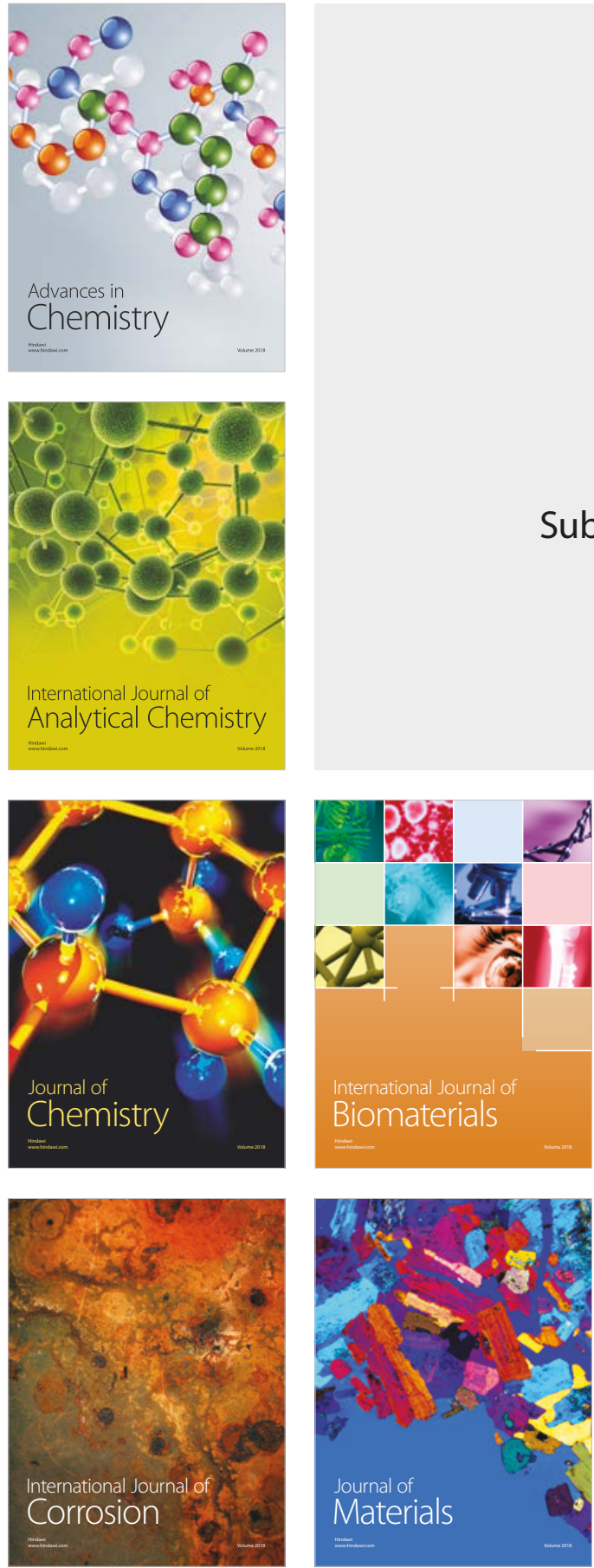

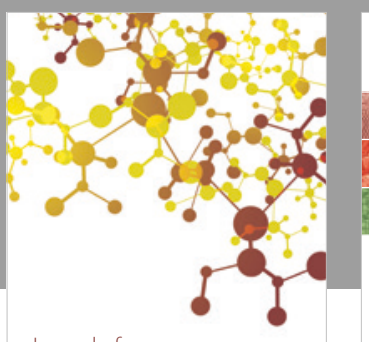

Journal of

Applied Chemistry
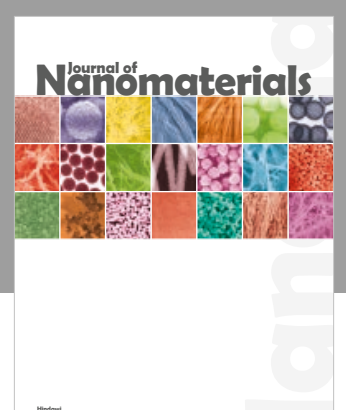

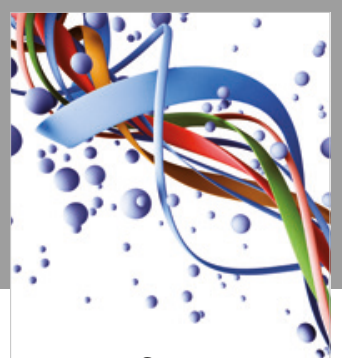

Scientifica

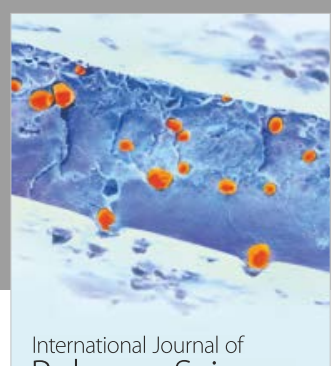

Polymer Science

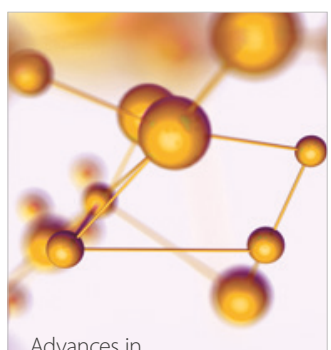

Physical Chemistry
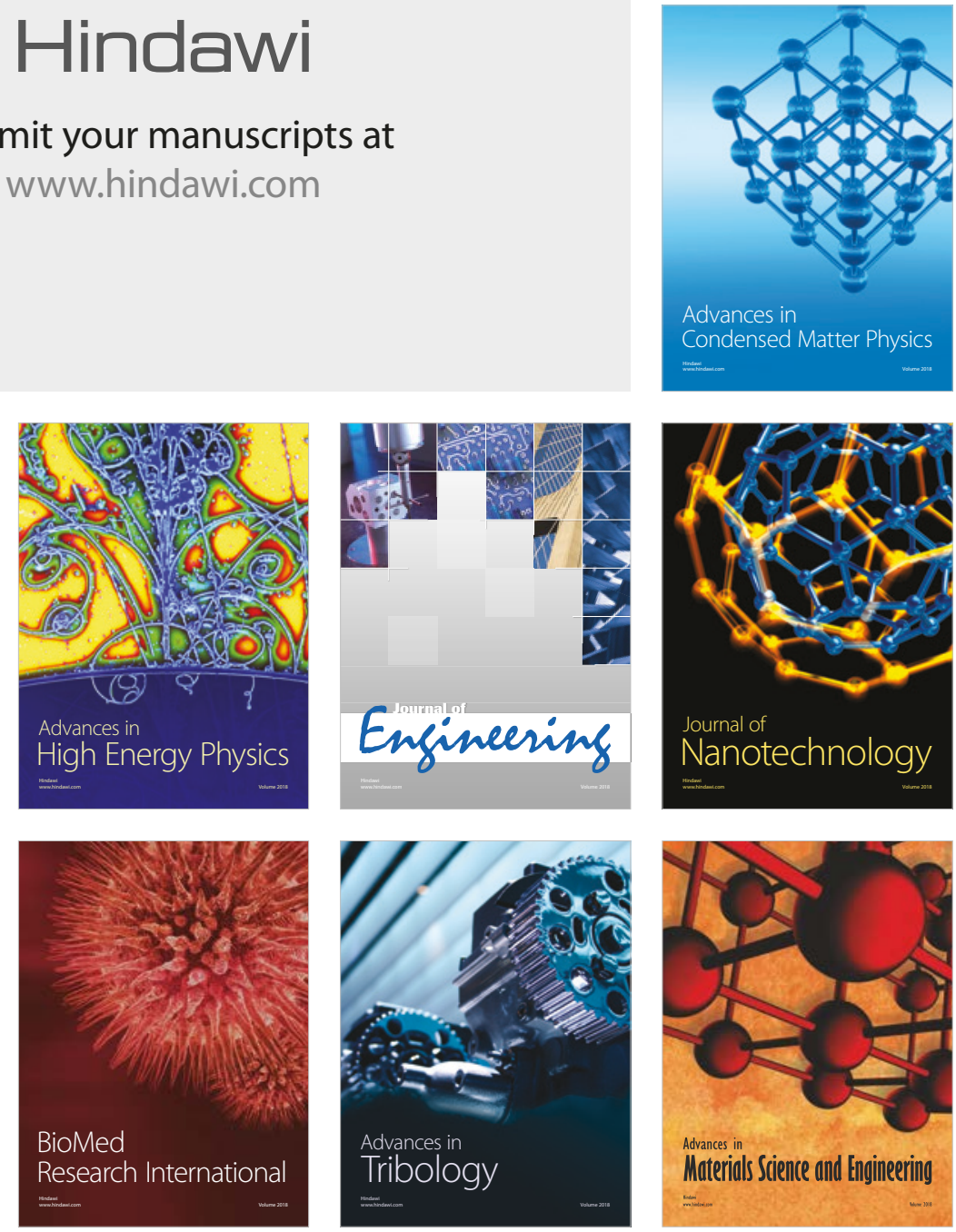